\title{
UNDERSTANDING THE INFLUENCE OF SOCIAL RESPONSIBILITY EDUCATIONAL INTERVENTIONS ON THE EMPOWERMENT OF FEMALE STUDENT-ATHLETES: A CASE STUDY USING CONSENSUAL QUALITATIVE RESEARCH
}

\author{
A Dissertation presented to \\ the Faculty of the Graduate School \\ at the University of Missouri \\ In Fulfillment of the Requirements for the Degree \\ Doctor of Philosophy \\ by
}

Dr. Alex Waigandt, Dissertation Supervisor

MAY 2014 
The undersigned, appointed by the Dean of the Graduate School Have examined the dissertation entitled

UNDERSTANDING THE INFLUENCE OF SOCIAL RESPONSIBILITY EDUCATIONAL INTERVENTIONS ON THE EMPOWERMENT OF FEMALE STUDENT-ATLETES: A CASE STUDY USING CONSENSUAL QUALITATIVE RESEARCH

Presented by Alicia (Hatcher) Malnati

A candidate for the degree of

Doctor of Philosophy

And hereby certify that, in their opinion, it is worthy of acceptance.

Dr. Alex Waigandt

Dr. Richard McGuire

Dr. Steven Osterlind

Dr. Gregory Holliday

Dr. Joseph Scogin 


\section{Acknowledgements}

A simple thank you to all of those who have supported me and loved me is not nearly enough. Countless individuals have touched my life and have inspired me in remarkable ways. What I value, how I think, and who I am is a reflection of interactions with these individuals. Here are a few who deserve special recognition for their help and support with this project:

To Dr. Alex Waigandt for providing an educational experience that will springboard my life and career to new places; To Dr. Rick McGuire for insisting on excellence and introducing me to the opportunity of a lifetime. You have awakened my spirit; To Dr. Greg Holliday for providing heartfelt wisdom, moments of peace, and a sense of clarity when I needed them most. And for always believing in me; To Dr. Steven Osterlind for making it so challenging to give in to qualitative research. And for your stories that brought life to statistics; To Judge Bob Bailey for sitting across the table in 2010 and asking what I thought. Things have truly come full-circle; To Dr. Joe Scogin for being the biggest puzzle piece to our dream come true. And for providing me a foundation when I felt like crumbling; To the University of Missouri staff and administration who let their hearts guide their work everyday to fulfill important core values; To Dr. Leslee Fisher for believing in me when you could have so easily given up; To my research team for helping me make sense of eight incredible interviews and bringing perspective to their experiences; and to the female student-athletes who agreed to let me ask them questions for an hour and ended up changing my life.

Finally, to all of my family, friends, and coworkers who gave me high-fives and the strength to keep going; To my mother, Connie, for loving me with every ounce of her 
being; To my father, Ward, for his unconditional support from across the planet; and to my husband, Peter, for never giving up on me. Six letters have quickly transformed our careers and lives, and I am filled with pure joy to continue the journey of life with you; my sincerest thank you to everyone. 


\section{Table of Contents}

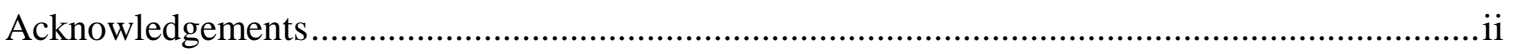

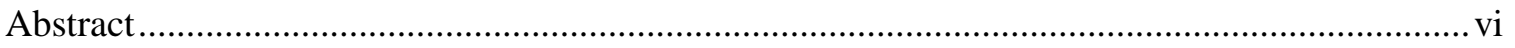

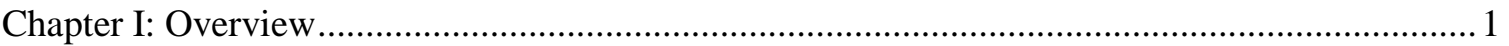

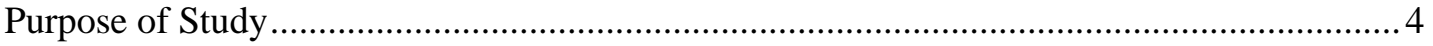

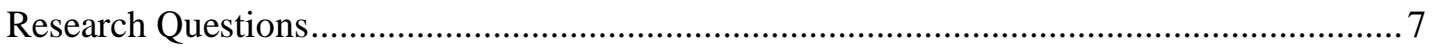

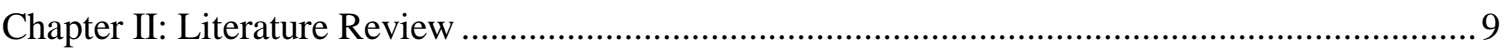

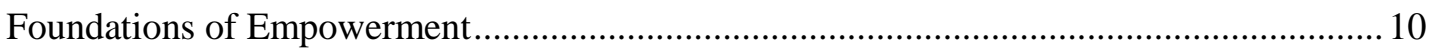

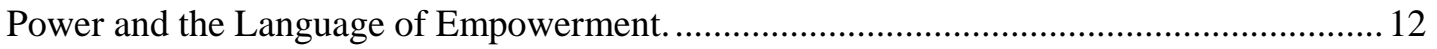

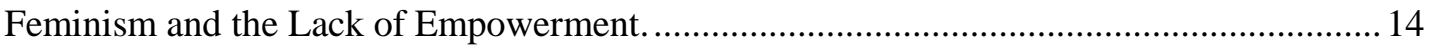

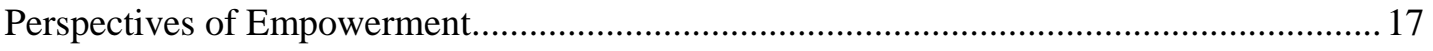

Psychological Empowerment: Power Within Yourself. .............................................................. 18

Theoretical Foundation of Psychological Empowerment ...........................................2 20

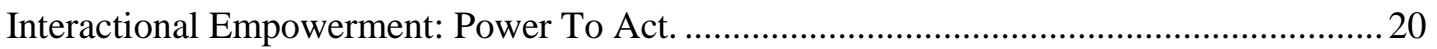

Theoretical Foundation of Interactional Empowerment.............................................22

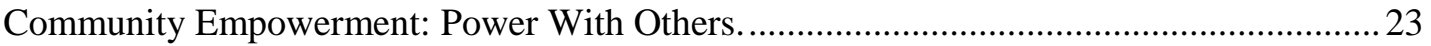

Theoretical Foundation of Community Empowerment ...............................................2 23

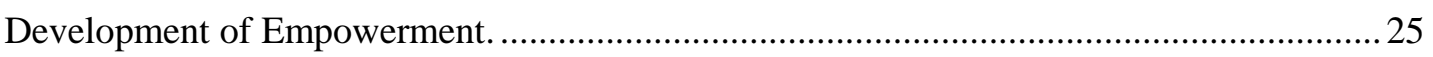

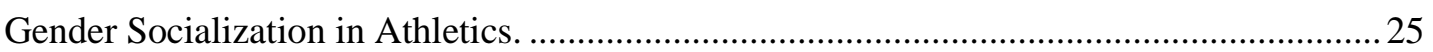

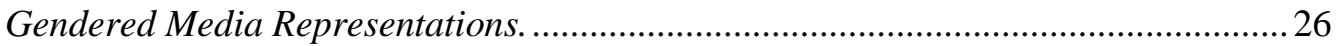

Social Responsibility Educational Interventions in Athletics...............................................2

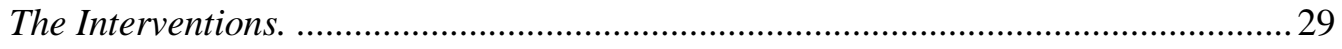

Theoretical Foundation of Social Responsibility Educational Interventions. .............. 30

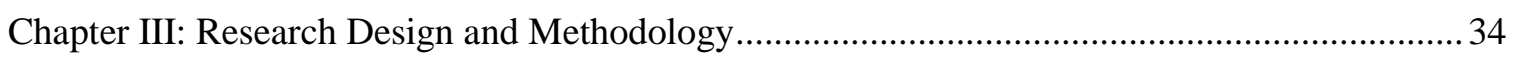

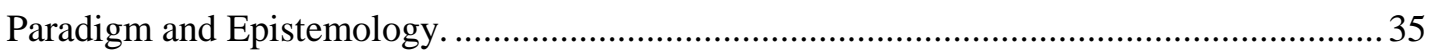

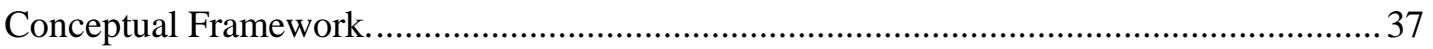

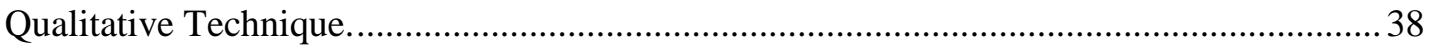

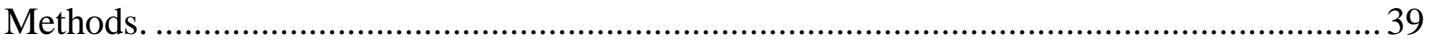

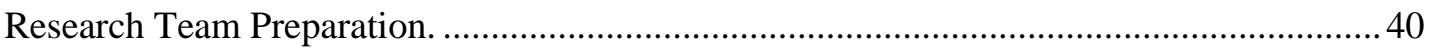

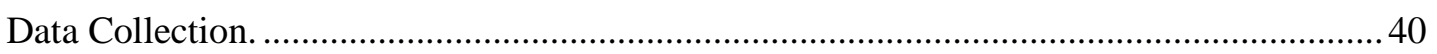

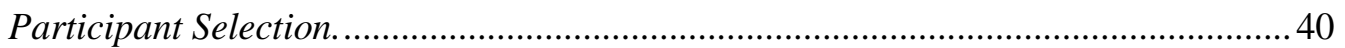

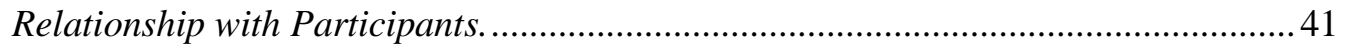

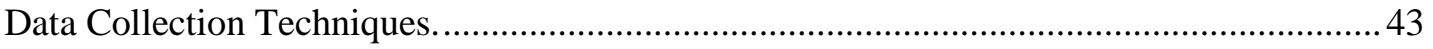

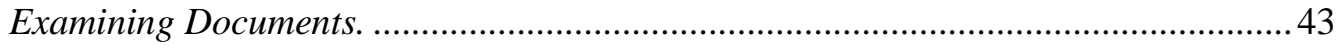

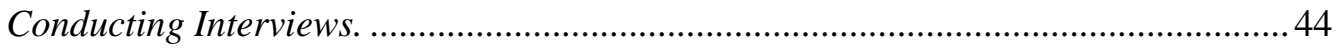




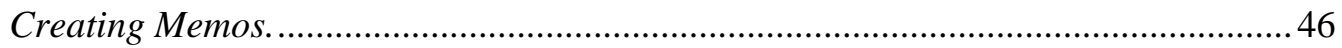

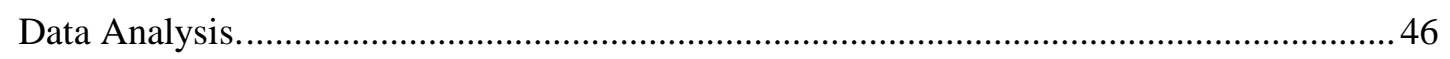

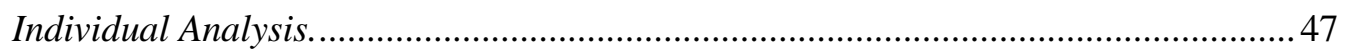

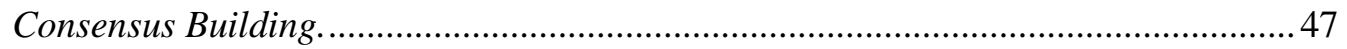

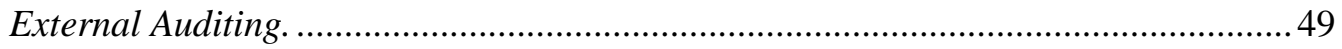

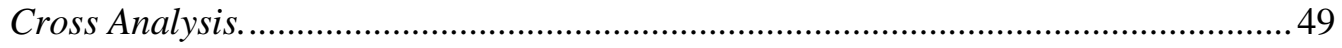

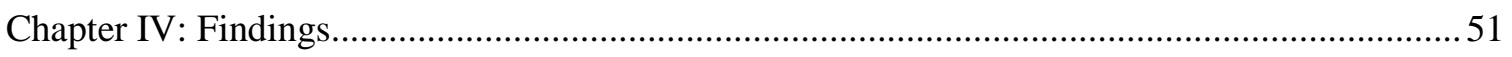

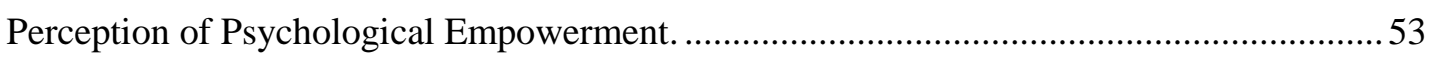

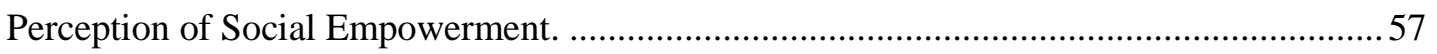

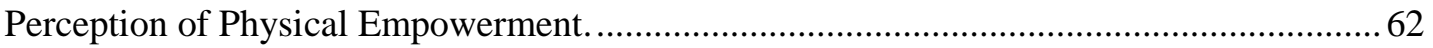

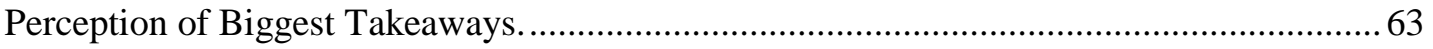

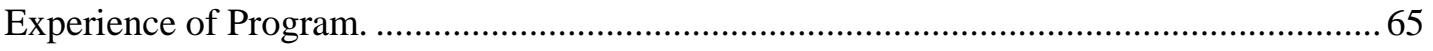

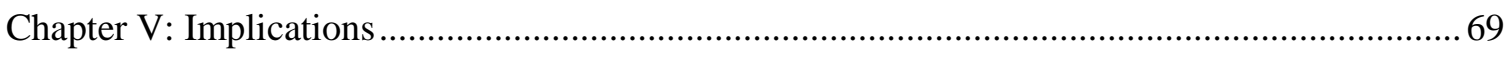

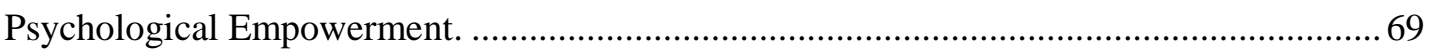

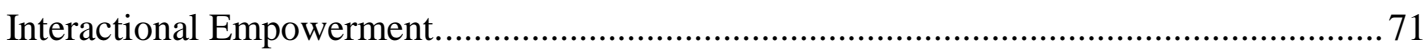

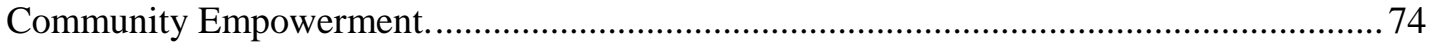

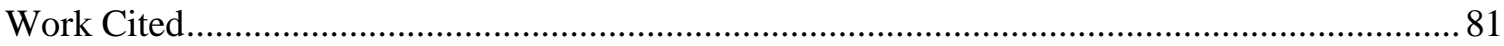

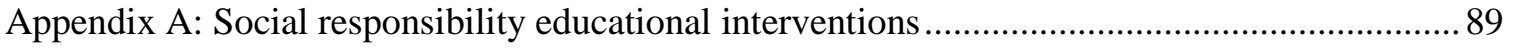

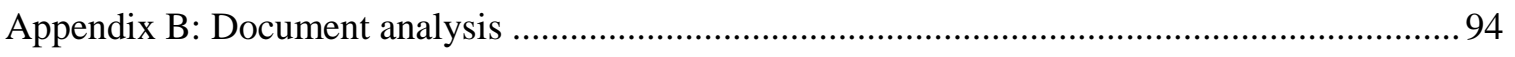

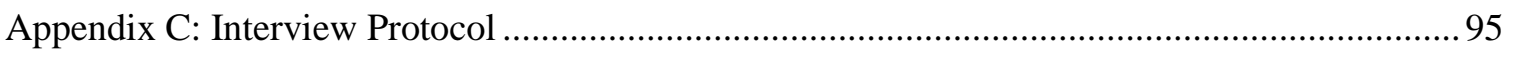

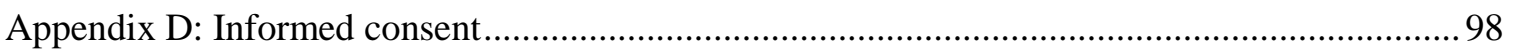

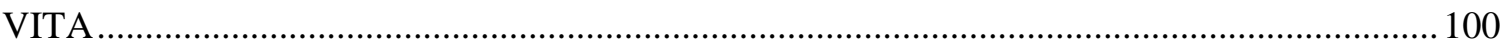


Understanding the influence of social responsibility educational interventions on the empowerment of female student-athletes: A case study using consensual qualitative research

\begin{abstract}
At a time when socially irresponsible behavior, alcohol abuse, and relationship and sexual violence are particularly prevalent on college campuses, empowering female student-athletes to live their best lives regardless of societal expectations is a vital pursuit for intercollegiate athletic departments and academic service professionals. Therefore, female student-athletes who participated in a social responsibility educational intervention were interviewed to explore their experiences of the program and to understand its influence on their experiences of empowerment.

Using consensual qualitative research, five domains were revealed: perception of psychological empowerment, perception of social empowerment, perception of physical empowerment, perception of biggest takeaways, and experience of program. Findings illustrate the importance and value of lighting a fire within a woman who believes in herself, who can act upon those beliefs, and who can build community around those beliefs. Findings also reveal a medium through which athletic department leaders can advance their efforts to empower female student-athletes through educational and personal development opportunities.
\end{abstract}




\section{Chapter I: Overview}

Socially irresponsible behavior, alcohol abuse, and relationship and sexual violence are serious social problems that do not escape the athletic environment. These behaviors are present in female student-athlete culture and are certainly problematic. In November 2009, soccer standout Elizabeth Lambert was suspended from her University of New Mexico team after shoving, punching, tripping, and yanking down Brigham Young University opponents (Hughes, 2009). In February 2010, Baylor basketball star Brittney Griner was suspended after hitting and breaking the nose of Texas Tech's Jordan Barncastle during a game (Crouse, 2010). Besides examples like these, research also reveals that student-athletes engage in binge drinking more often than their non-athlete peers (Wechsler, Davenport, Dowdal, Grossman \& Zanakos, 2010) and that female student-athletes in particular are twice as likely as their male counterparts to engage in sexual risk-taking behaviors after heavy episodes of drinking (Huang, Jacobs, \& Derevensky, 2009). Although many topics in intercollegiate athletics deserve attention, examples like these display the problematic behavior of female student-athletes. Other times, behavior toward female student-athletes is concerning.

In October 2011, two female students at Marquette University were attacked by several male student-athletes, were forced to perform sexual acts on them, and were then shunned after reporting the crime (Haggerty, Lighty, \& St. Clair, 2011). High school athletes in the San Francisco Bay area were suspended in October 2012 after creating a "Fantasy Slut League," which was loosely based on "Fantasy Football” and involved them "drafting" female students - unbeknownst to most of them - and earning points for documenting sexual activity with them (News Fix, 2012). And in one of the most horrific 
examples of all, George Huguely, a former University of Virginia lacrosse player, was convicted in August 2012 and sentenced to 23 years in prison for killing his ex-girlfriend Yeardley Love (Payne, 2012). In a culture where women engage in behavior that misaligns with goals and purposes of sport and where women are seen as objects of sexual desire, empowering female student-athletes to live their best lives regardless of societal expectations is a vital pursuit.

However, because of the powerful incentive to win athletically, winning in the area of social responsibility may seem to provide little benefit. Young women may not have a concussion as a result of poor coverage like a football player, but when female student-athletes develop in an arena that over appreciates their sexual appeal and undervalues their contributions to sport and society, culture stagnates. Research by Mean and Kassing (2008) reveals that although women are represented substantially more in sport as a result of Title IX legislation, hyper-sexualized images of female athletes leads to decreased respect. Without question, women in American culture gain prominence and attention by wearing revealing clothing, taking photos in sexually suggestive poses, and using their bodies as transmitters of femininity.

Therefore, the development of strong, brave, and courageous women in sport is necessary to break the cyclical transmission of knowledge and to enhance societal perceptions. Creating communities of empowered women who challenge the status quo of expectations related to womanhood; who value, respect, and appreciate their true selves; and who display these qualities through action is a primary goal and outcome during the empowerment process. Because of the characteristics associated with 
athleticism, including strength and determination, female student-athletes are ripe with potential for this type of development.

However, much of the research on student-athletes examines volunteerism (Gayles, Rockenbach, \& Davis, 2012), alcohol consumption (Martens, Dams-O’Connor, Duffy-Paiement, Gibson, 2006), and their experiences in the college environment (Kezar, 2004); few studies directly examine their development of empowerment. This lack of research suggests that a gap in the literature exists related to the development of empowerment in female student-athletes. Still, research on overall empowerment reveals three distinct categories: psychological empowerment, or power within; interactional empowerment, or power to; and community empowerment, or power with (Nikkhah, Redzuan, \& Abu-Samah, 2012). The three areas, which will serve as the guiding approach for examining the development of empowerment, address personal evaluation of the self, abilities to influence environments, and unification of individuals toward a common purpose. Helping female student-athletes grasp the meaning of their behavior can create the internal desire to make positive change within their immediate environments that is necessary for social progress. Lighting the fire within a woman who believes in herself, who can act upon those beliefs, and who can build a community around those beliefs contains inherent and widespread benefits. Because of these valuable contributions, developing women through all three empowerment domains is a prized outcome of the college experience and should help institutions and athletic departments meet specific, strategic goals.

Furthermore, because college athletics is situated in the environment of United States higher education, athletic departments hold a direct obligation to facilitate 
empowerment in female student-athletes. Without a doubt, female student-athletes should leave the intercollegiate athletics environment as empowered individuals capable of navigating a diverse social world, not simply as athletes who can outperform an opponent. Empowering the nearly 200,000 female student-athletes (NCAA.org) in the National Collegiate Athletic Association (NCAA) is also especially important considering they will likely grow into the mothers, grandmothers, mentors, and leaders of future generations.

Social responsibility educational interventions in intercollegiate athletics have the potential to fulfill this common educational purpose of empowerment through studentathlete awareness of genuine social concerns, development of their individual moral compasses, and returned attention to the hybrid dynamic of education through sport. Specifically, developing the three forms of empowerment helps begin the process.

Most importantly, social responsibility educational interventions provide a medium through which athletic department leaders can shape the female student-athlete experience. Facilitating these components means that attention is returned to the development of student-athletes as individual people during the pressure-filled and performance-driven environment of academic capitalism, the trend of non-profit institutions engaging in the competitive marketplace (Slaughter \& Rhoades, 2004).

\section{Purpose of Study}

Gaining insight into how female student-athletes make sense of social responsibility educational interventions is crucial for understanding their experiences of empowerment. These understandings possess the potential to shape additional research on the topic and the structure of current interventions, which includes the primary goal of 
developing female student-athletes into their authentic selves, free of the traditional social constraints and expectations related womanhood. Continuing to develop women with the capabilities required to influence the cultural landscape and distribution of power is vital to the heart of American higher education.

Accordingly, even though few researchers have examined the development of empowerment in intercollegiate athletics, the fundamental purpose and goal of this inquiry is to understand the influence social responsibility educational interventions have on female student-athletes, specifically through the three empowerment domains. Understanding their experiences of a specific program with these goals is a primary route to achieving understanding. Additional and supplementary goals also shape the inquiry.

Maxwell (2005) describes two types of research goals - practical goals and intellectual goals. Practical goals focus on accomplishing an objective, meeting a need, or changing a situation. Practical goals for this study include (1) continuing to develop female student-athletes as strong, confident, and complete individuals and (2) establishing and validating a platform for departments across the country to empower female student-athletes.

Intellectual goals, in contrast, are focused on understanding a topic, gaining insight into the nature of an experience, or answering a question that previous research has not adequately addressed. Intellectual goals for this study include (1) understanding how female student-athletes make sense of their development through the interventions; (2) gaining insight into the experiences of psychological, interactional, and community empowerment for female student-athletes; and (3) adding to the empirical understanding and contributing to the research base on addressing the development of female student- 
athlete empowerment during the college experience. The researcher's personal experience as a student-athlete also shapes the direction of the inquiry and the overall research purpose.

Although the researcher's personal experiences as a student-athlete were filled with some of the most gratifying and rewarding experiences of her life, creating even better experiences for others is a large part of the motivation for this study. Enhancing the college experience through thoughtful examinations of self, improving the extent to which other women view their capabilities to create positive change, and truly empowering female student-athletes to live their best lives are perhaps the most fulfilling components of her work in holistic student development. In fact, during her experience, the researcher did not have the direct opportunity to engage in this type of programming and therefore, at times, did not apply strength of self and confidence in her abilities to daily life as much as she now would have hoped. Subsequently, she was somewhat envious of the student-athletes receiving these interventions, but was also eager to understand their experiences of empowerment and to bring research to the literature base.

Furthermore, as a professional in the field of student-athlete support services, returning emphasis to the actual experiences student-athletes live everyday while simultaneously meeting NCAA academic regulations and departmental objectives is also part of the motivation for this study. In the world of numerical results like graduation rates and visual signifiers of success like national championships, which are of course important, the subjective nature of student development topics lends itself to the possibility of administrators overlooking its value. The desire to validate holistic student development mechanisms in intercollegiate athletics without a doubt guides the purpose 
of this study. It also creates a tremendous approach to the researcher's work and guides her career goals - to develop student-athletes holistically as an upper-level administrator. These motives underpin the purpose of the study and are inextricably linked to the research questions.

\section{Research Questions}

With the purpose firmly grounded in holistic student development and female student-athlete empowerment, specifically facilitated through social responsibility educational interventions, three primary research questions guide the inquiry: (1) How do female student-athletes experience the social responsibility educational interventions?,

(2) How do these experiences fit with psychological, interactional, and community empowerment?, and (3) To what extent do the female student-athletes feel empowered as a result of participating in the interventions? These overarching questions form the foundation of the study.

Additional sub-questions also contribute to understandings of female studentathlete empowerment. These questions include: (1) What are the biggest messages gained from the social responsibility educational interventions?, (2) How have the interventions contributed to the female student-athletes' assessments of self?, (3) What changes in attitude or behavior have the female student-athletes demonstrated as a result of the interventions?, (4) How have the interventions influenced the overall development of the female student-athletes?, and (5) What type of environment have the interventions created in relation to community empowerment? These secondary questions provide the necessary details for inquiry. And because of the interpretative nature of these research questions, a qualitative design is appropriate. A thorough review of the literature related 
to the foundations of empowerment and the development of empowerment provide further insight into the inquiry. 


\section{Chapter II: Literature Review}

For the past 25 years, research on empowerment has influenced disciplines such as public health, social psychology, multicultural and feminist counseling, social work, health promotion, management, and nursing (Cattaneo \& Chapman, 2010; BradburyJones, Irvine, \& Sambrook, 2007; Kabeer, 1999; Conger \& Kanungo, 1988). Empowering experiences have the ability to transform understandings, perspectives, behaviors, and attitudes toward the demands of life. Developing individuals to live their best lives can also influence effort, outcomes, and ultimately the trajectory of human experiences. With attention to the physical and emotional well-being of individuals more pervasive in society now than ever before, understanding empowerment and the dynamics of empowering experiences is essential for those seeking to improve human lives (Bradbury-Jones, Irvine, \& Sambrook, 2010).

At the same time, the prominence of intercollegiate athletics intensifies as the financial landscape of higher education dwindles. During difficult economic times, university leaders increasingly rely on revenue generation alternatives to compensate for declining state appropriations to higher education. These financial shortfalls propel higher education institutions to become further engaged in the competitive marketplace, an activity Slaughter and Rhoades (2004) term academic capitalism.

Applied to intercollegiate athletics, this trend of non-profit institutions acting more businesslike can bring challenges including the following: (a) a view that necessitates increased efforts toward recruiting athletically stellar but perhaps academically under-prepared student-athletes, (b) an approach to departmental goals that may overlook attention to holistic student development, and (c) a perspective that defines 
the college experience primarily through outcomes of athletic competition. The possibility of increasing donor revenue, although important, as a result of departmentwide championship seasons could lure athletic leaders into neglecting holistic studentathlete development and eventually the mission of higher education. Because developing students as complete individuals is central to the core values of higher education, developing empowerment in female student-athletes through social responsibility education is a valuable topic.

Thorough analysis of empowerment, specifically through three distinct perspectives, reveals the intricate landscape of the research base. Examination of gender socialization and social responsibility education provides ample context for understanding the nature of empowerment during the college experience. Furthermore, explanations reveal the distinct need to understand the influence of social responsibility educational interventions on the empowerment of women participating in intercollegiate athletics. Collectively, this approach synthesizes contributions from various empowerment researchers and theories of human development into a coherent mechanism that helps explain need to the develop empowerment in female studentathletes.

\section{Foundations of Empowerment}

Research on empowerment consistently emphasizes its positive contributions to health and well-being (Spencer, Maxwell, \& Aggleton, 2008). Lindgren, Patriksson, and Fridlund (2002) found that after participating in what they described as an empowering program, the female athlete participants reported feelings of self-confidence and belongingness, feelings of being seen and confirmed, and an awareness of issues typically 
associated with women. Studies like these reveal potential outcomes of educational interventions related to empowerment, but researchers often understand the construct through different lenses. Therefore, gaining a complete picture of what empowerment actually is receives much attention in the literature.

Although researchers agree empowerment is a valuable component of human development, ambiguity encompasses much of the literature base. Some researchers describe empowerment as a process, an outcome, or combination of both; some define empowerment in a phrase and others delineate its elements; and some describe levels of situation-specific empowerment, such as in an academic setting, whereas others describe it as a holistic or global measure (Bradbury-Jones et al., 2007). Researchers consistently note the difficulties in appropriately capturing the construct of empowerment and have often made comparisons to Justice Stewart's 1964 opinion on defining obscenity: I shall not today attempt further to define the kinds of material I understand to be embraced within that shorthand description; and perhaps I could never succeed in intelligibly doing so. But I know it when I see it. (Jacobellis v. Ohio, p. 198) Capturing the essence of empowerment is no simple task, but personally experiencing the feelings associated with it and seeing the outcomes in others are qualities to which many can relate. However, the challenges associated with understanding empowerment hold even deeper roots in history.

In 1933, a National Government Organization activist stated, "I like the term empowerment because no one has defined it clearly yet, so it gives us a breathing space to work it out in action terms before we have to pin ourselves down to what it means," (as cited in Batliwala, 1993, p. 48). Although the assertion is nearly 80 years old, researchers 
have still not clearly revealed the nature of empowerment, so the message is still applicable today.

To that extent, Sigmund Freud's approach to love also provides insight into the dynamics of empowerment. Freud viewed love as "essentially one experience that can take a variety of forms, and therefore, any attempt to unpack love into its constituent parts will destroy the essential experience" (as cited in Compton \& Hoffman, 2013, p. 104). Although many current researchers, perhaps including happiness experts Sonja Lyubomirski and Martin Seligman and relationship expert John Gottman, would likely reject Freud's notion that constructs are one-dimensional and that social science research will destroy their experience, the struggle to capture the essence of empowerment still rings true today. The literature base continues to overwhelmingly reveal a nebulous understanding of empowerment. A review of the fundamental components of the word itself provides important groundwork for this study.

\section{Power and the Language of Empowerment.}

With the foundation of the word empowerment bounded in the term "power," understanding its etymology, the origin of a word and the historical development of its meaning, provides additional insight into research. The Latin root of the word power is "potere," which literally means "to be able to and have the ability to choose." The Oxford English dictionary also links it to the word "potent," which implies having great influence or effect. And its mid- $17^{\text {th }}$ century origin derives from the French word "poeir" and the Medieval Latin term "posse," both of which mean "be able."

Additionally, the Oxford English dictionary defines empowerment as "giving someone the authority or power to do something, enabling someone to do something, or 
making someone stronger and more confident, especially in controlling their life and claiming their rights." These qualities however are not applicable to every individual and every experience. As such, much of the foundational research focuses on the experiences of women who lack these qualities the most and who live in the most challenging social and economic conditions.

However, poverty, although crucial, is not the only influence on women's disempowerment - the structure of society and the expectations it has in relation to a woman's place in the world perpetuate inequities. Simply stated, not everyone who lacks power can gain it due to structural and environmental constraints (Cattaneo \& Chapman, 2010). Hence, the process of empowerment typically occurs when power is unequally distributed, where existing structures perpetuate the advantages of some instead of others, and when individuals take action to remedy the inconsistencies. The challenges associated with the lack of empowerment, specifically those based in socialization and its resulting hierarchy, play out in gender expectations and behavior, which suggests women have "internalized their social status as persons of lesser value" (Kabeer, 1999, p. 440).

Pierre Bourdieu's (1977) term “doxa” also helps make sense of this phenomenon related to the internalization of women's value. Doxa characterizes the aspects of culture that are "so taken-for-granted they have become naturalized into the traditions and beliefs that exist beyond argumentation" (as cited in Kabeer, 1999, p. 442). Women in particular often accept these norms and customs within the everyday structure of life, which often translates into the acquiescence of household chores, submissive role acceptance, and relationship violence, among others. A brief examination of the women's movement 
provides necessary context for the development of empowerment in female studentathletes.

\section{Feminism and the Lack of Empowerment.}

In July 1848, the feminist movement gained momentum in the United States when Elizabeth Cady Stanton, Lucretia Coffin Mott, and other Quaker women composed the Declaration of Sentiments at the Seneca Falls Convention in New York. Among other notable demands, the women advocated for full legal rights, educational equality, equal compensation, the right to collect wages, and the right to vote. Not until August 20, 1920 did the $19^{\text {th }}$ Amendment grant American women the de jure right of suffrage, which is perhaps one of the most notable indicators of first-wave feminism.

Four decades later, the National Organization for Women (NOW) formed, and by 1970, grew to include more than 400 local chapters. As urgency consistently increased, the feminist movement expanded to include topics related to employment, education, childcare, contraception, abortion, workplace equality, and changing family roles, which are all topics aligned with de facto rights typically associated with second-wave feminism.

In addition, Title IX of the Education Amendment of 1972 prohibited discrimination in educational programs based on sex and is perhaps one of the most influential pieces of legislation related to the involvement of women in athletics (Ware, 2011). One year later, the landmark decision in Roe v. Wade legalized abortion and with it came sizeable amounts of antifeminist backlash. In her book, Susan Faludi (1991) argues that this backlash related to reproductive freedom, which political conservatives challenged based on religious beliefs, continues to inhibit women's equality. She exposes 
the prevailing narrative that women have achieved global equality and challenges it primarily by emphasizing that the pressure to avoid the active pursuit of equality is fundamentally what continues to inhibit women's full participation in society.

Third-wave feminism emerged during the time of Faludi's book and is now a leading approach in the feminist literature base. Differing definitions of womanhood, specifically those based on the ethnic, religious, and cultural backgrounds of individuals, characterize the nature of third-wave feminism. Embracing diversity, advocating for change, and deconstructing dichotomous conceptions of femininity are also necessary components.

Although feminism improved the conditions of women across the nation, gender disparities were still evident in the suppression of foundational human rights. In the United States, women were not allowed admission into medical schools or law schools until the 1900's, and they only began working outside the home primarily in the 1940's when the demands of Word War II necessitated their involvement. And even when they did participate in economic jobs, women were still not considered equals.

In 1913, the president of the Civil Service Commission stated that the United States government would no longer hire women stenographers because "blondes were too frivolous and brunettes were too chatty" (as cited in Kalantari, 2012, p. 246). Twenty years later a General Electric official explained that, "women were hired because they could be paid less than men" (as cited in Kalantari, 2012, p. 246). Although much of these overt and visual signifiers of inequity are since removed, long-lasting traditions related to gender expectations remain. The division of labor once necessary to sustain economic life, such as men completing traditionally masculine duties of hunting and 
cultivating and women accepting childbearing and the traditionally feminine obligation of homemaking, remains in tact even after monumental shifts in technology. Historical expectations continue to define women's roles today.

Across much of the world, women often participate in the phenomenon known as "the second shift" where they hold jobs and then return home to complete nearly all of the housework (Menon, 2013). Nationally, women hold 16.9 percent of political positions, which is 2 percent lower than the international average and ranks $91^{\text {st }}$ worldwide (Lawless \& Fox, 2012). Women remain underrepresented in faculty positions across the country and are overrepresented in positions as schoolteachers, administrative assistants, and nurses (Hargens \& Long, 2002; Kalantari, 2012). And although women also constitute more than 50 percent of college graduates and academically outperform their male counterparts in every college major, they earn 80 cents for every dollar men earn in equivalent positions with equivalent knowledge and experience (Kalantari, 2012). In addition, the glass ceiling, an intangible barrier within hierarchy that prevents women and individuals from ethnic minority groups from obtaining upper-level positions, continues to limit their full potential in the professional environment and helps explain these differences (Johns, 2013). Embedded in culture are beliefs and actions that perpetuate social inequities relative to women, which are often reflected in low perceived abilities to influence social conditions. Because of all of these reasons, developing empowerment in female student-athletes is an important goal. Specifically examining one type of intervention, for this study social responsibility education, is needed to begin developing preliminary understandings of how to best facilitate the empowerment process. 
Nonetheless, to understand the social conditions of women in some parts of the world, in 1999, Kabeer compared scores of empowerment across nine countries, including Nigeria, Bangladesh, and Nepal. She used women's access to resources, levels of agency, and levels of achievement as the prominent criteria. Her results revealed that empowerment for these women meant increases in their role at home, emancipation, improved levels of marriage equality, and financial autonomy. Again, the proliferation of studies on empowerment primarily focus on improving the living conditions of women in developing countries and often includes topics such as land ownership, which are more fundamental in nature than modern conceptualizations. Empowerment researchers also examine differences between location and time, the influence of specific interventions, and the implications on desired policy outcomes (Kabeer, 1999).

Altogether, the literature base reveals that power can be developed, enhanced, and sharpened, which can lead to empowerment (Nikkhah, Redzuan, \& Abu-Samah, 2012). It also reveals three primary classifications that are best understood in context psychological empowerment, or power within; interactional empowerment, or power to; and community empowerment, or power with. This perspective combines theories of human development and social change into three valuable components to provide influence to those without it, improve human experiences, and enhance values of human rights and equality.

\section{Perspectives of Empowerment.}

Through an examination of the literature base, three distinct understandings of empowerment emerged: psychological empowerment, interactional empowerment, and community empowerment. Because each provides a specific contribution to overall 
empowerment, the trio will serve as the guiding perspective of empowerment for this study. It is also the perspective through which the experience and influence of social responsibility educational interventions will be examined.

\section{Psychological Empowerment: Power Within Yourself.}

Psychological empowerment, or "power within" (Nikkhah, Redzuan, \& AbuSamah, 2012), relates to the internal, psycho-emotional factors that influence selfperceptions. Based on the nature of these individual perceptions, power within also implies differing levels, interpretations, and performances of empowerment.

Psychological empowerment for a middle-aged, Black man is very different than that of a college-aged, female student-athlete. An empowering experience for a person who grew up in poverty looks very different than that of a person who was raised in a middle-class family. Because of the intricacies of human thought, perception, and behavior, a single definition that accounts for all expressions and interpretations of psychological empowerment is challenging, if not impossible, to define.

Despite its complexity, researchers make efforts to characterize the nature of psychological empowerment. Noteworthy interpretations include the following: "The process of enabling people to choose to take control over and make decisions about their lives" (Rodwell, 1996, p. 309); “enabling to act” (Chandler, 1992, p. 65); "a process in which individuals learn to see a closer correspondence between their goals, a sense of how to achieve them, and a relationship between their efforts and life outcomes" (Mechanic, 1991, p. 159); “a mechanism by which people, organizations, and communities gain mastery over their affairs" (Rappaport, 1987, p. 122); and "a social process of recognizing, promoting, and enhancing people's abilities to meet their own 
needs, solve their own problems, and mobilize the necessary resources to feel in control of their lives," (Gibson, 1991, p. 359). Each contribution is valuable because psychological empowerment can encompass all of these ideas when applied to individuals in specific contextual settings.

Other researchers understand psychological empowerment through descriptions of its fundamental components, and accordingly, much of the research focuses on one or more variables believed to fall within the scope of empowerment (Foster-Fishman, Salem, Chibnall, Legler, \& Yapchai, 1998). Although Zimmerman's (1995) model of empowerment incorporates many layers, his understanding of psychological empowerment primarily includes the elements of competence, efficacy, and mastery (Peterson, Peterson, Agre, Christens, \& Morton, 2011).

Cattaneo and Chapman (2010) also emphasize understanding psychological empowerment through its components and highlight a sense of individual control, personally meaningful and power-oriented goals, self-efficacy, knowledge, and competence. Guido-DiBrito \& Batchelor (1988) include leadership development, using integrity to value themselves and others, cultural competency, understanding perspective, communicating vision, collaboration, and critical thinking as the most important elements of psychological empowerment.

However, not all researchers make the distinction between types of empowerment and therefore do not categorize their approach as psychological empowerment even though their interpretations indicate and confirm its presence. Nonetheless, models that address psychological empowerment hold a large base in Bandura's (1977) social learning theory and his related concept of self-efficacy. 


\section{Theoretical Foundation of Psychological Empowerment.}

Bandura's social learning theory suggests that behavior is learned through observations from social interactions and experiences in the environment. Men and women learn how to act and what to think through modeling behaviors and experiences with social norms. In addition, perceived self-efficacy, beliefs individuals hold about their own capabilities to exercise control over their level of functioning and other events that affect their lives, largely determines aspirations, motivation, and overall accomplishments (Bandura, 1993). "Efficacy beliefs influence how people feel, think, motivate themselves, and behave," (p. 118). Self-efficacy addresses multiple facets of human development, and many directly relate to empowerment. Collectively, these models emphasize developing confidence, enhancing self-esteem, and influencing perceptions of personal control to create meaningful human experiences, which can vastly influence psychological empowerment. Essentially, "power within" is the personal assessment of self. Part of further understanding the landscape of empowerment requires an examination of how these cognitive elements are applied.

\section{Interactional Empowerment: Power To Act.}

Interactional empowerment, or "power to" (Nikkhah, Redzuan, \& Abu-Samah, 2012), relates to decision-making authority, problem solving skills, and abilities to take action. It also includes the element of choice, which necessarily involves the possibility of alternative options (Kabeer, 1999). No amount of confidence or efficacy can empower an individual without choice. Conger (1988) also notes that empowerment implies enabling rather than simply delegating. "The process of delegation is too constrictive in scope to accommodate the complex nature of empowerment," (p. 474). Individuals must 
not only have some glimpse of autonomy but also support and resources from others for successful interactional empowerment. Accordingly, like psychological empowerment, context is crucial for understanding interactional empowerment.

The extent to which individuals have the ability to make decisions and the forms those decisions take vary across setting. How a mother of three in a rural town exercises and displays choice is much different than that of a corporate executive living in New York City. As Kabeer (1999) notes, "It is highly unlikely that all members of a given society will give equal value to different possible ways of 'being and doing,"' (p. 4). Interactional empowerment relates to those actions and implies that empowered individuals use cognitive appraisals to act upon their environment.

As described previously, Zimmerman (1995) includes these contextual factors in his understanding of psychological empowerment but also addresses aspects of interactional empowerment. His interactional component includes critical awareness, an understanding of the sociopolitical environment, and direct actions that are expected to influence outcomes (Peterson, Peterson, Agre, Christens, \& Morton, 2011). Zimmerman recognizes the value and influence of psychological empowerment on the behavioral and action-oriented elements in an environment.

McWhirter (1991) also addresses interactional empowerment through his model that highlights the power present in human experiences and includes "an awareness of the power dynamics at work in their life context, the development of skills and capacity for gaining some reasonable control over their lives, exercising this control without infringing upon the rights of others, and supporting of the empowerment for others in their community" (p. 224). McWhirter's model addresses the psychological elements of 
empowerment with the development of individual skills and again recognizes interactional components with awareness and action.

Similarly, Cattaneo and Chapman's (2010) model of empowerment focuses on the interactional elements of personally meaningful and power-oriented goals that are aimed to change social influences. The focus on human behavior change highlights the importance of context. However, not all researchers distinguish interactional empowerment from other forms although their interpretations indicate and confirm its presence. Nonetheless, these models of interactional empowerment hold a large base in self-determination theory.

\section{Theoretical Foundation of Interactional Empowerment.}

Deci and Ryan's (1977) self-determination theory posits that all human beings have fundamental psychological needs for competence, autonomy, and relatedness that, when fulfilled, contribute to intrinsic motivation. Research indicates that intrinsic motivation leads to a greater likelihood of action and intentionality to pursue meaningful goals (Deci \& Ryan, 2012). Deci and Ryan highlight the need to enhance intrinsic motivation so individuals can make meaningful progress toward their goals and feel in control of the direction of their lives. Increasing intrinsic motivation through this lens is likely to contribute to individual action. Developing the burning desire within female student-athletes to improve their lives and the experiences of others is therefore an essential component of the empowerment process.

Collectively, these models of interactional empowerment emphasize developing awareness, enabling choice, and taking action. Essentially, "power to" is the ability to 
influence environments. The third and final type of empowerment provides meaning on the societal level.

\section{Community Empowerment: Power With Others.}

Community empowerment, or “power with” (Nikkhah, Redzuan, \& Abu-Samah, 2012), involves the influence of group action. In their research, Spencer, Maxwell, and Aggleton (2008) describe community empowerment as "the mobilization of empowered individuals into communities to take action against the disempowering effects of the socio-political environment," (p. 348). Uniting a group of individuals with high levels of self-worth, self-efficacy, and self-determination are ripe conditions for profound social change, even if that group is as small as a family or as large as an entire population of people. Context is crucial because the variety of forms that community empowerment takes in each of these settings varies substantially.

Nikkhah, Redzuan, \& Abu-Samah (2012) also recognize the strength of collective action and highlight the greater potential for achievement when groups act together instead of when individuals act alone, such as in the gay rights movement or the women's movement. Again, not all researchers label their interpretations as community empowerment even though their understandings indicate and confirm its presence. Nonetheless, these models of community empowerment draw upon Robert D. Putnam's concept and interpretation of social capital and Paulo Freire's notion of critical consciousness raising.

\section{Theoretical Foundation of Community Empowerment.}

According to Putnam, social capital refers to the networks and norms of reciprocity and the trustworthiness that arises as a result of those interactions. "Civic 
virtue is most powerful when embedded in a sense network of reciprocal social relations. A society of many virtuous but isolated individuals is not necessarily rich in social capital," (InFed.org). Hence, empowerment requires individuals working together to create outcomes that benefit themselves and society.

In addition, Freire's concept of critical consciousness raising, the process by which people move from a position of unquestioning acceptance of the social order to a critical perspective on it (Minkler \& Cox, 1980) facilitates the involvement of communities to create goals and act upon them. Through the process of identifying needs and potential solutions to those needs, communities define and take control over the most salient issues to them. Social capital and critical consciousness raising bring awareness to the belief that societal structures can be modified and recognize the value in bringing together individuals to create social change. Developing networks of empowered female student-athletes who question the status quo is therefore an essential component of the empowerment process.

Collectively, these models of community empowerment emphasize expanding awareness and collective action to bring social transformation. Essentially, "power with" is uniting individuals toward a common purpose. Thorough analysis reveals empowerment as a dynamic and contextually layered process that influences individual and group action. It certainly involves a number of complementary social constructs that can be developed, but like happiness, a magic formula is elusive. No single perspective, including this one, will create global empowerment for all individuals, in all communities, in all contextual settings - empowerment is too complex. However, the threefold approach of psychological, interactional, and community empowerment helps 
make sense of the complex construct in a more coherent manner. In the model, perception is critical, and developing elements of empowerment, at the very least, can increase overall levels of it. For female student-athletes, reinforcement of these characteristics during the college experience is imperative. An examination of the developmental aspects of college students and female student-athletes provides further insight into the dynamics of understanding empowerment.

\section{Development of Empowerment.}

Like the construct itself, developing empowerment is a multifaceted process. Although many aspects influence its development, gender socialization and social responsibility educational interventions, particularly for female student-athletes, are two important components for this study.

\section{Gender Socialization in Athletics.}

Given its popularity and presence in American culture, sport provides a substantial avenue for the transmission of gender norms. The masculine context of sport is often seen as incongruent with traditional understandings of women, which includes attributes such as individualism, competitiveness, aggressiveness, power, strength, and toughness. Participation in college athletics further develops these beliefs and values, which result from the extension of social traditions and conceptualizations of masculinity and femininity (Steinfelt, Zakrajsek, Carter, \& Steinfelt, 2011). As a result, these norms guide but also constrain athletes in relation to how they view themselves and their abilities to influence their environment.

Additionally, balancing the desire to maintain dual identities is challenging. Research reveals that women negotiate between standards of traditional male athleticism, 
yet at the same time "attempt to manage expectations of maintaining culturally desirable aspects of femininity including attractiveness, heterosexuality, and relationships" (Steinfelt et al., 2011). The desire for successful sport participation also contributes to female athletes valuing traits typically associated with masculinity while also expressing pride in their strength and an overall feeling of empowerment (Steinfelt et al., 2011). Social norms, values, and ideologies are reinforced through gender socialization in college athletics, and often, performing the dual identity of a woman and an athlete becomes challenging.

Furthermore, research reveals that a high degree of conformity to masculine norms is linked with more health-risk behaviors, binge drinking, sexual aggressiveness, and greater endorsement of rape myths (Steinfelt et al., 2011). It also reveals that a high degree of conformity to feminine norms is linked with greater risk of disordered eating. Unquestioning acceptance of these norms without a doubt hinders the empowerment process. Sexualized images of women in the media further enhance these gender norms.

\section{Gendered Media Representations.}

Through media images, women athletes are often exploited through sexual desirability and objectification the female athletic body. Often, these images display values of attractiveness and sexuality rather than athletic performance:

Sportswomen are portrayed in feminine stereotypical roles, emphasizing beautifully proportionate and conditioned bodies, posing in an erotic or sexually available way. There is an emphasis on 'cosmetic fitness' - a 'fashion model' body shape - and a slim appearance. Sportswomen are framed as objects of the male reader's gaze. (Brandt \& Carstens, 2005, p. 235) 
Often, sports publications focus on the outward beauty of women athletes rather than physical abilities and accomplishments. These nonperformance images cater to the male audience, strip women athletes of their voice, and further inhibit the development of empowerment in female student-athletes.

In fact, photos of female tennis stars Tatiana Golovin, Daniela Hantuchova, and Maria Kirilenko in Sports Illustrated's "Swimsuit 2009" issue accentuate their physical attractiveness and sexualize their bodies as they push their breasts together, squat on beaches in skimpy bikinis, splash in the water, look seductively into a camera from above, and appear sexually available while lying on a bed. These sexualized images are problematic because they "excise women athletes' highly fit bodies from an athletic context and repackage them as desirable objects," (Daniels, 2009, p. 403). When society overvalues a woman's body for its sexual desirability rather than intellectual capabilities, women's ability to gain or hold power diminishes. Images like these ignore their physical strength and power as professional competitors and establish another hurdle to overcome during the empowerment process.

Daniels (2009) adds that changes to the portrayal of women are needed to get "sport-involved girls and women to think of themselves in more instrumental ways and less appearance-focused ways" (p. 404). Attention to athleticism can prompt women to views themselves in terms of physical abilities rather than outward appearances. Among other valuable goals, overcoming gender stereotypes, especially those related to expectations as women athletes, is a central theme in the social responsibility educational interventions and in developing empowerment.

Social Responsibility Educational Interventions in Athletics. 
Student-athletes have the unique ability to electrify national audiences, excite entire communities, and accomplish lofty team goals. Female student-athletes specifically hold the ability to continue paving the way for future generations of women. The field of intercollegiate athletics enables student-athletes to learn about themselves personally, professionally and athletically - true education through sport. However, because of its popularity, student-athletes are often held to a higher standard of behavior than nonathletes whether it is fair or not. Social responsibility, the set of attitudes and beliefs that guide sound behavioral decisions on and off the competition floor, now plays an increasing role in the lives of student-athletes and provides an established medium through which empowerment can be developed in intercollegiate athletics.

Social responsibility educational interventions have the potential to educate students on genuine social concerns, guide their individual moral compasses, and return attention to the developmental goals associated with higher education. Encouraging student-athletes to discover for themselves what it means to be a man or woman in today's society is crucial for their lives in and out of athletics. Communicating with fellow student-athletes on topics like body image and sexuality will undoubtedly encourage an examination of their perspectives. And developing a strong sense of self through improved understandings and appreciation for the historical roots of athletics will further guide their college experience. How student-athletes handle tough situations as a result of these experiences influences the reputation of an institution. How studentathletes approach challenges, interact with peers, and create authentic connections with one another shapes the college environment. Most importantly, the ways in which female student-athletes understand themselves, their ability to influence the environment, and the 
collective atmosphere of support to do so is fundamental to the empowerment process.

Collectively, social responsibility educational interventions enhance the studentathlete experience through opportunities for self-reflection and examinations of personal development topics. Questioning accepted norms that inhibit women from acting out their authentic selves is vital for female student-athletes to feel empowered, to take a leading role in their lives, and to help others do the same. Most importantly, the interventions provide the environment necessary to empower an entire population of individuals and are valuable investments for intercollegiate athletic departments. For this study, five interventions will serve as an avenue to further understand the influence of social responsibility educational interventions on the empowerment of female student-athletes.

\section{The Interventions.}

Because of the visibility of intercollegiate athletics and the cultural expectations resulting from the gender socialization process, cultivating empowerment, specifically in female student-athletes, is a crucial component to fulfilling the mission of higher education institutions and athletic departments nationwide. Incorporating initiatives that facilitate individual growth into the cultural fabric of college athletics is crucial to helping student-athletes navigate a diverse social world as empowered individuals.

Social responsibility as a distinct initiative was implemented at the selected institution after several student-athletes gained attention for inappropriate behavior. Through a student-led group, departmental leaders learned that alcohol was perhaps the biggest influence on these types of behavior. Social responsibility was then explicitly included in the institution's 2011 strategic plan along with several related objectives. Specific and separate programming for men and women was then implemented to address 
the concerns. Women in the department who were suited to provide guidance in the development of the programming were selected to create and deliver the interventions. And although the primary goal of the overall initiative was to encourage improved behavior among all student-athletes, social responsibility provides an appropriate avenue to empower female student-athletes. Full descriptions of the five interventions are available in appendix A. Collectively the sessions included a celebration of female athletic accomplishments; the history related to women's participation in sports; tough conversations on rape and sexual assault; relationship building with peers; examinations of the expectations of women in athletics; and presentations on many related topics.

\section{Theoretical Foundation of Social Responsibility Educational Interventions.}

Although relatively little research has been conducted on the student-athlete population and social responsibility as a whole, questions arise about the extent to which student-athletes benefit from their overall college experience, how their participation in athletics influences their learning and personal development, and how participation in athletics influences psychosocial elements of developing competence, establishing mature relationships, and identity formation (Gayles, 2009). However, Kezar (2004) challenges the structure of intercollegiate athletics and states, "Athletics is an example of an area that has become so dominated by economic gain that it may never be able to incorporate educational values again" (p. 443). Intercollegiate athletics, like many aspects of social life, contains severe imperfections. Therefore, programming targeted specifically to learning, development, and growth is essential to counterbalance the pressure to perform athletically. Developing empowerment through social responsibility is a start to addressing these types of concerns. Astin's I-E-O model, Astin's theory of 
student involvement, and Chickering's psycho-social model of student development provide a solid theoretical backbone to this type of development.

Astin's (1985) Input-Environment-Outcome (I-E-O) model, a theory that suggests student outcomes are a function of the prior experiences and characteristics students bring to college and the types of experiences they have while in college, provides a foundation for developing empowerment. Astin's research reveals that college outcomes related to knowledge, attitudes, and beliefs are a function of inputs, or demographic variables and student experiences, and environments, or the experiences students have in college (Pascarella \& Terenzini, 2005). The I-E-O model is particularly suited for social responsibility educational interventions because female student-athletes have prior experiences that shape their development in college. The intervention experiences create pieces of the environment that contribute to student outcomes, which could lead to advances in the empowerment process.

Additionally, Astin's (1985) involvement theory focuses on how learning and development occur as a result of the amount of physical and psychological energy students invest in the academic and social aspects of college. Without a doubt, studentathletes will learn the most when they are actively involved and engaged in academic and social programming. The social responsibility educational interventions provide an avenue for this type of development but outcomes certainly depend on levels of engagement. Including female student-athletes in discussions, establishing small groups during learning exercises, providing bonding experiences with peers, and bringing guest panelists can increase student engagement and are elements included in the interventions. 
Finally, Chickering's psychosocial model of student development also provides a foundation for developing empowerment in female student-athletes. Its seven components include the following: developing competence, managing emotions, moving through autonomy toward independence, developing mature interpersonal relationships, establishing identity, developing purpose, and developing integrity (Valentine \& Taub, 1999). Because the interventions address components of each, insight into the dynamics of developing empowerment in female student-athletes is enormous. In combination, the three theories provide ample support for the development of female student-athlete empowerment through social responsibility initiatives.

In intercollegiate athletics, establishing women as strong and valuable contributors of the student-athlete experience is essential to empowerment and its related outcomes of social transformation. Specifically with women, Nikkhah, Redzuan, and Abu-Samah (2012) recommend that empowerment interventions should create opportunities for social interaction with other women where they can recognize their strengths, reflect on their experiences, and create strategies to achieve positive change. Bandura (1995) also suggests that individuals "who are persuaded verbally that they possess the capabilities to master given tasks are likely to mobilize greater sustained effort than if they harbor self-doubts and dwell on personal deficiencies when difficulties arise" (p. 4). Research clearly reveals that student development initiatives ought to facilitate the conversations and critical thinking skills necessary to increase levels of selfefficacy, which are again included in the interventions.

Overall, this approach to develop empowerment through social responsibility education assumes that individuals who have increased feelings of power, self-efficacy, 
and self-determination are more likely to achieve desired outcomes. Education is a crucial mechanism to disrupt feelings of powerlessness, to replace traditional role definitions with more sophisticated conceptualizations of womanhood, and ultimately to empower the female student-athlete population. Collectively, developing the three-fold perspective of empowerment through social responsibility educational interventions is appropriate. The research design and methodology allows for this type of inquiry. 


\section{Chapter III: Research Design and Methodology}

Qualitative inquiry enables researchers to investigate the nature of lived experiences through insight into individual and group perspectives. Richards and Morse (2007) note that qualitative methods are highly appropriate when "preemptive reduction of the data will prevent discovery" (p. 30). Because of the ambiguous research base on empowerment and the complexities involved with gender socialization and student development, qualitative inquiry was necessary to examine the influence of social responsibility educational interventions on female student-athletes. Maxwell (2005) highlights the importance of research design in qualitative research and notes that the design is essentially the logic and coherence of a study - "the components of your research and the ways in which these relate to one another" (p. xii). To reveal results and make conclusions that accurately capture the experiences of the female student-athlete participants, all components of the research design must be complementary.

With female student-athlete empowerment, a sound research design, which specifically incorporates feminism as the paradigm; constructionism as the epistemology; empowerment, gender socialization, and student development theories as the conceptual framework; a case study as the qualitative technique; individual interviews as data collection; the constant comparative method as the primary form of data analysis; and triangulation for ensuring validity and trustworthiness provides a cohesive approach for understanding the topic. Together, these elements display the value of understanding women's experiences from their individual perspectives and were well-suited to the nature of qualitative research. Feminism and constructionism framed the overarching structure of the inquiry and provided an avenue for preliminary examination of the 
research design and methodology.

\section{Paradigm and Epistemology.}

A feminist paradigm, or worldview that situates women's experiences at the heart of knowledge and understanding, provided the lens through which female student-athlete empowerment in intercollegiate athletics was examined. Understanding how female student-athletes make sense of the social responsibility educational interventions provided them a voice in the traditionally male-dominated field of intercollegiate athletics. Recognizing the value in how they construct pieces of their identity as a result of the intervention placed their values, beliefs, and attitudes at the center of understanding. And asking them direct questions in an environment where they can comfortably express their interpretations of the interventions validated their experiences. Feminism as a paradigm offered female student-athletes a voice in how they did or did not develop empowerment through the interventions. And creating the programming through internal staff members and graduate students who knew the women mitigated some of the power dynamics present that could silence them.

The overarching goals of feminism served as the paradigm from which the urgency and need to understand the experiences of women originated. This notion translates to the value of exploring the holistic development of college women, and in particular, the empowerment of female student-athletes, which certainly includes those from typically underserved racial and ethnic groups. Feminism as a worldview validates the experiences of women and without a doubt shaped the context of this study. This worldview is evident in the overall design through the research questions and the 
interview protocol that validated their lived experiences of empowerment in intercollegiate athletics.

Constructionism, an epistemology that suggests meaning is not discovered but instead is created, was appropriate for understanding female student-athlete empowerment. "Knowledge is not simply transmitted from teacher to student. Learners actively construct and reconstruct knowledge out of their experiences in the world," (Kafai \& Resnick, 1996, p. 3). Empowerment is an inherently individual social construction where meaning, interpretation, and perspective are central to understanding. This social construction of knowledge lends itself to the rejection of positivist, big-T truth where the goal is to facilitate meaning-making rather than to distinguish between right and wrong behaviors.

Additionally, research on social constructionism by Newton, Deetz, and Reed (2011) contributes to understandings of female student-athlete empowerment. Newton, Deetz, and Reed describe alterations to subjective reality as an individual's ability to influence what is interpreted and perceived as a pre-determined environment (2011). If female student-athletes are socialized into the organization's objective reality, in this case, the norms and collective understanding of behavior associated with membership to the organization of intercollegiate athletics, what is perceived as appropriate for female student-athletes becomes a benchmark for the subsequent thoughts and behavior of others. Unfortunately, cultural norms and team standards often portray women as passive, thin, attractive, heterosexual, and promiscuous individuals who serve as objects to consumers of a sexualized media (Harrison \& Secarea, 2010). 
Through constructionism, social responsibility educational interventions can attempt to puncture the social veil of expectations through further understanding that individuals create the social world. Supporting female student-athletes into the wholehearted belief that they can exist outside social expectations and can make a difference on the piece of Earth they stand is perhaps the most important outcome of the social responsibility educational interventions. Constructionism enabled the examination of female student-athlete perspectives of empowerment, which led to a useful research product, particularly for professionals seeking these types of outcomes. Because studentathletes can gain meaning through the interventions, specifically those related to power within, power to, and power with, constructionism was appropriate for the inquiry. The conceptual framework provides further clarification of the research design and methodology.

\section{Conceptual Framework.}

Miles and Huberman (1994) describe the conceptual framework as "a visual or written product that explains...the key factors, concepts, or variables and the presumed relationships among them" (as cited in Maxwell, 2005, p. 33). Simply stated, the conceptual framework is created through examination of literature and theory and is not found in one particular place. This examination necessitates critical understanding and thorough communication of research but also includes interaction with the environment. In fact, Locke et al. (1993) suggests that "the best introduction to the current status of a research area is close association with advisors who know the territory" (as cited in Maxwell, 2005, p. 34). Because of the researcher's personal involvement with intercollegiate athletics and the social responsibility initiative, the conceptual framework 
includes theories of empowerment, gender socialization, and student development.

The three perspectives of empowerment - power within, power to, and power with - help gauge the nature of female student-athlete experiences. Theories of gender socialization highlight several influences and inhibitors to their perspectives of empowerment. And approaches to student development highlight the role intercollegiate athletic departments play in developing female student-athletes as empowered individuals through social responsibility efforts. Additionally, the researcher's personal involvement as a student-athlete and in the development of social responsibility initiatives provides perspective to the research environment. Collectively, the conceptual framework addressed factors that contribute to female student-athlete empowerment, acknowledged the vital role of athletic departments to holistically develop student-athletes, provided a lens through which understanding levels of empowerment is achievable, and recognized the interconnected relationship between all components. The case study served as a valuable mechanism to further understand the influence of social responsibility educational interventions on female student-athlete empowerment.

\section{Qualitative Technique.}

Because case studies reveal details about a particular phenomenon from the viewpoint of participants and use multiple sources of data, it was an appropriate qualitative technique for understanding perceptions related to the influences of empowerment. Bogdan and Biklen (2007) describe the case study as "a detailed examination of one setting, a single subject, a single depository of documents, or a particular event" (p. 271). Yin (1989) recommends using the case study approach when “'how' or 'why' questions are being posed, when the investigator has little control over 
events, and when the focus is on a contemporary phenomenon within some real-life context" (p. 13). Proper methods are vital to the accuracy of research findings and conclusions.

\section{Methods.}

For qualitative inquiry, methods commonly refer to the specific procedures and approaches to data and how those research decisions reflect the overall design. Specifically, consensual qualitative research (CQR) served as the primary method for the study. The CQR process "highlights the use of multiple researchers, the process of reaching consensus, and a systematic way of examining the representativeness of results across cases," (Hill et al., 1997, p. 519). In addition, CQR incorporates elements of constructivism with its acknowledgement of "multiple, equally valid, socially constructed versions of 'the truth', (Hill et al., 2005, p. 197) but also incorporates pieces of postpositivism with a consistent interview protocol and an emphasis on disclosing researcher biases.

In addition, with $\mathrm{CQR}$, emphasis is placed on the "inner experiences of individuals" and is particularly suited for studying "events that are hidden from public view, are infrequent, occur at varying time periods, have not been studied previously, or for which no measures have been created," (p. 204). Because the foundation of CRQ aligns with the qualities of the social responsibility interventions, it was an ideal approach for the study. Altogether, CQR served as a valuable tool to examine the experiences of female student-athlete empowerment and reduced the bias inherent associated with a single individual conducting analysis. Research team preparation, data collection, and data analysis (individual analysis, consensus building, coding schemes, external auditing, 
cross analysis, and member checking) are essential components of CQR and formed the overall methods.

\section{Research Team Preparation.}

That research team consisted of the primary researcher, two faculty members, three graduate research assistants, and one external reviewer. These individuals were educated in qualitative methodology and except for the primary researcher, were familiar, but not involved, with the social responsibility interventions. Each of the team members also read Hill et al. (1997), Hill et al. (2005), and two exemplar manuscripts that used CQR. Additionally, all of the research team members discussed assumptions and biases, a necessary point of transparency in any qualitative research. Having additional individuals involved who challenged each other and brought outside perspective strengthened the study and is a benchmark of CQR.

\section{Data Collection.}

Superior data collection helped fulfill the explanatory nature of qualitative research. Participant selection, relationship with participants, and data collection techniques served as the primary avenues for obtaining valuable data for the study.

\section{Participant Selection.}

Choosing individuals who can provide the information needed to address research questions is perhaps the most important consideration for participant selection in qualitative research. With this type of purposeful sampling, individuals are selected deliberately who can reveal insight into experiences that cannot be obtained as well from other sources (Maxwell, 2005). In fact, Weiss (1994) suggests that these decisions are not samples at all, and instead refers to them as panels - "people who are uniquely able to be 
informative because they are expert in an area or were privileged witness to an event" (as cited in Maxwell, 2005, p. 88). Because qualitative research is founded on understanding lived experiences, the importance of appropriately selecting individuals whose perspectives serve as an indication of some larger meaning cannot be overemphasized. Among others, Creswell (2002) highlights goals of achieving representativeness and capturing heterogeneity.

Specifically selecting female student-athletes whose experiences are considered typical provides a far greater chance that conclusions based on their experiences adequately represent the average members of the population. Although somewhat opposite of the first goal, selection of heterogeneous and diverse female student-athlete experiences also ensures that the conclusions adequately represent the range of variation, rather than only those that are considered typical.

To achieve this variation, the researcher invited eight female student-athletes to participate in individual interviews and aimed to include approximately two per grade level, approximately 50 percent white and 50 percent non-white, and a variety of sport teams. The interviews lasted approximately one hour and were conducted to theoretical saturation. Participants chose pseudonyms to maintain their confidentiality.

\section{Relationship with Participants.}

Because they are the means through which qualitative research is often directly accomplished, relationships with participants are critical (Maxwell, 2005). They underlie the kind of information gained and require continuous restructuring. Hammersley and Atkinson (1995) term this involvement reflexivity - "the fact that the researcher is part of the social world he or she studies" (as cited in Maxwell, 2005, p. 82). In addition, Hill et 
al. (2005) emphasize the mutual influence that the researcher and the participant have on each other during the process of CQR. Understanding the interactive nature of these relationships is crucial for excellent qualitative inquiry.

Because of professional interactions with the female student-athletes at the selected institution, relationships with participants were perhaps closer than what is typical. Working with the female student-athletes on aspects of their college experience, including major and class selection, career preparation, mentoring and advising, and postgraduation plans, are fundamental components of the researcher's profession. Seeing a female student-athlete once or twice a week and engaging in conversations ranging from classroom progress to challenges with family was not an uncommon experience for the researcher. Additionally, the researcher's intimate involvement in planning and designing the social responsibility educational interventions contributes to her relationship with participants. They see and experience the outcomes her work. Both types of involvement inherently possess advantages and disadvantages.

Developing rapport with participants was less complicated than usual. Many of the female student-athletes were familiar with the researcher's participation in college athletics and therefore could view her as a more credible individual who could relate to their experiences. However, Seidman (1998) emphasizes that too much or too little rapport can hinder the quality of data gained, which is particularly important given that the researcher is the instrument during qualitative inquiry (as cited in Maxwell, 2005, p. 83). Establishing herself as a sophisticated researcher while cautiously and successfully navigating personal connections with participants were important elements. 
Still, Lawrence-Lightfoot and Davis (1997) note "relationships that are complex, fluid, symmetric, and reciprocal - that are shaped by both researchers and actors - reflect a more responsible ethical stance and are likely to yield deeper data and better social science" (as cited in Maxwell, 2005, p. 84). From this perspective, personal connections and direct involvement offers valuable insight into the nature of female student-athlete empowerment that might not be revealed otherwise. Engaging in sincere self-reflection and active critical thinking related to the influence of these relationships were critical elements to minimizing researcher bias.

Furthermore, the Athletic Director, Executive Associate Athletic Director, Senior Woman Administrator, and several additional administrators within the athletic department at the selected institution were aware of the intent and methods of the study. Relationships with participants clearly are important elements of the research process, and the information gained from the participants further reflects the research design and methodology.

\section{Data Collection Techniques.}

For the study of female student-athlete empowerment, examining relevant documents, conducting in-depth interviews, and creating memos served as three primary data collection techniques (Swanborn, 2010; Starke, 2006). Appling these valuable techniques ensured a sound research study and aligned with the overall methodology.

\section{Examining Documents.}

Any written documents related to the topic are valuable tools in the data collection process, including program proposals, self-evaluations, research reports, meeting minutes, and organizational letters, memos, and agendas (Bogdan \& Biklen, 
2007). To maintain confidentiality, the strategic planning goal was the primary source of information for the examination of documents, which is available in appendix B. This goal created the foundation for the entire social responsibility educational intervention and informed the process of holistic student-athlete development, specifically the development related to empowerment. Interviews were the next essential component to data collection in qualitative research.

\section{Conducting Interviews.}

Without a doubt, interviews are the most common method of data collection in qualitative research, which is largely founded in the constructive nature of social interaction and the meaning-making process (King \& Horrocks, 2010). Accordingly, when determining how to best study happiness, Lyubomirsky and others found it "empirically acceptable to simply ask people about their perceived happiness and life satisfaction, and therefore, allowed participants to define terms of happiness by 'whoever lives inside a person's skin"” (Myers \& Diener, 1995, p.11). Hence, individual interviews where participants can construct their own perspectives and meaning of their experiences revealed insight into perspectives of female student-athlete empowerment.

Individual, semi-structured interviews were valuable research tools to gain further insight into the dynamics of developing empowerment in female student-athletes through social responsibility educational interventions. Individual interviews revealed in-depth information about personal experiences through questions related to background and demographics, behaviors, opinions, values, feelings, knowledge, and senses (King \& Horrocks, 2010). The semi-structured style established guidelines for the conversations but allowed flexibility in exploring particularly relevant topics that naturally arose 
(Merriam, 2009). This approach also aligned with Hill et al.'s (2005) recommendations for $\mathrm{CQR}$ :

The participant teaches the researcher about the phenomenon, and the researcher influences the participant through the probes used to help the participant explore his or her experiences. The interviewer's role is typically as a trustworthy reporter trying to uncover what the participant truly believes, rather than someone who engages with the participant in a deeply relational way to construct meaning (p. 197).

Examples of questions include: (a) What has your experience been like with the program?, (b) What are some of the biggest messages you've taken away? and (c) What do you think the programming is doing for the female student-athletes as a whole?

In addition, disconfirming questions helped ensure that an accurate and appropriate picture of the three empowerment domains was gathered. These types of questions include (a) What is the most influential factor toward how you view yourself?, (b) In what ways does the programming not help you act upon your beliefs?, and (c) Tell me about what the programming does not do in respect to creating an environment for all female student-athletes. These one-on-one interviews were conducted until theoretical saturation was achieved and included probing questions when appropriate. Three pilot interviews were conducted prior to the participant interviews to ensure quality, flow, and appropriateness. The interview protocol is available in appendix C.

Furthermore, all interviews were conducted during the summer of 2013, were held in a location of the participant's choosing, were audio-recorded, and were transcribed by a transcription service. The primary researcher reviewed the transcription 
documents and compared them to audio-recordings to ensure accuracy. Written, informed consent, which is available in appendix $\mathrm{D}$, was gained with each of the participants. Memoing served as the third element of data collection techniques.

\section{Creating Memos.}

Case study researchers use memoing to log thoughts and feelings related to elements of interviews and observations. Bogdan and Biklen (2007) emphasize the importance of these reflections during qualitative data collection and note that memos are "usually part of the field notes and contain ideas that become the starting point for analysis and interpretation" (p. 273). Memos are crucial components to the research process because they will help the research team remember thoughts, feelings, insights, and reactions related to the empowerment process as they occur. "The horror of that moment," the King went on, "I shall never, never forget." "You will though," said the Queen, "unless you make a memorandum of it" (as cited in Maxwell, 2005, p. 12). The importance of memos for this study cannot be overemphasized. As such, thorough and thoughtful memos that include thick and rich descriptions will provide valuable data (Merriam, 2009). Together, examining documents, conducting interviews, and creating memos facilitated the data analysis process, the next component of the methods.

\section{Data Analysis.}

Analysis for case study data using CQR is similar to other qualitative approaches and most importantly includes individual analysis, consensus building, external auditing, and cross analysis. Collectively, the four elements helped create a trustworthy study using CQR. 


\section{Individual Analysis.}

Coding served as the primary method of individual data analysis for the interviews. Bogdan and Biklen (2007) describe it as the process of sorting data into manageable pieces based on any defining characteristic in an excerpt of data. To begin the process, transcripts of the eight interviews were given to each of the member of the research team. Each researcher then independently conducted line-by-line analysis of the content while keeping in mind not to summarize or make conclusions from the data but to pull participant experiences into a form that is "concise, clear, and comparable across cases" (Hill et al., 2005, p. 200). Researchers kept memos of their thoughts during the process to gain a clearer sense of the emergent ideas and themes. These memos ranged from as formal as a reflexive journal or as informal as notes in the margins. The second step in data analysis for the study was consensus building.

\section{Consensus Building.}

One of the most essential and fundamental components of $\mathrm{CQR}$ is the consensus building process. To ensure integrity, "mutual respect, equal involvement, and shared power" must be present among researchers (Hill et al., 2005, p. 197). The CQR process values a diversity of viewpoints, incorporates common and uncommon ideas, and can help "unravel complexities and ambiguities" in the data (as cited in Hill et al., 2005, p. 197). Applied to the study of female student-athlete empowerment, the consensus building process began with a two-hour meeting with all members of the research team to discuss and challenge themes discovered during the individual analyses. Discussing differences of opinion and feelings toward the data required team members to have strong interpersonal skills and a healthy amount of respect for each other (Hill et al, 2005). If 
any discrepancies arose, the group would have referred to the audio-recorded interview for confirmation or clarification of data.

In addition, during the process of navigating through the data, consistent "winnowing and sifting" allowed the individual themes to cluster into categories and eventually into domains, or essential overarching themes (Bogdan \& Biklen, 2007, Hill et al., 2005), and core ideas, or "summaries of the data that capture the essence of what was said in fewer words and with greater clarity" (Hill et al., 2005, p. 200).

Furthermore, during the consensus building process, the researcher used the constant comparative method and returned to previous interviews, memos, and literature to examine recurring topics. Consistently reading interview transcripts, observational notes, documents, and memos facilitated thinking and analytic insights, which is a cornerstone of the constant comparative method. This approach aligned with Coffey and Atkinson's (1996) recommendation of "never collecting data without substantial analysis going on simultaneously" (as cited in Maxwell, p. 95) and Hill et al.’s (2005) recommendation of "returning to the raw data to ensure the accuracy of the placement of core ideas into categories and examining the categories to see whether they can be revised" (p. 201).

To make this possible, all members of the research team provided descriptions of their assumptions and biases to refer to throughout the consensus building process. At the end of a two-hour session, the group created a set of initial domains and core ideas from the data. The primary researcher then created a table of these schemes for the group to reflect on before the next meeting. A second meeting of two hours included further 
reflections on domains and core ideas until the group reached consensus. This process aligned with the recommendation of Hill et al. $(2005,2007)$.

\section{External Auditing.}

Another strength of the CQR process is external auditing. Questioning and critiquing the placement of raw data into core ideas and domains is at the heart of the external auditor's role (Hill et al., 2005). Including an outside perspective that is not influenced by the potentially harmful phenomenon of groupthink strengthened the trustworthiness of the study. With the study of female student-athlete empowerment, the external auditor received all eight interviews, reflected on the groups' domains and core ideas, and then provided written, detailed feedback. Again, the external auditor, who was not present during the either of the two-hour research team meetings, helped ensure that the data was "faithfully represented" in the domains and core ideas (Hill et al., 2005, p. 201). The external auditor also played an important role in the next step of the data analysis process.

\section{Cross Analysis.}

Cross analysis, a specific way of checking and charting findings, is another important step in the CQR process. Once the external auditor's feedback was incorporated, the primary researcher and the lead faculty member reviewed the eight interviews and individually created a frequency table of the number of participants who mentioned each of the themes. Once the frequency tables were created, they compared findings and discussed any differences. Based on Hill et al.'s (2005) recommendation, the following classification system was used: general if the theme applies to all cases or all but one case, typical if the theme applies to at least half of the cases, and variant if the 
theme applies to less than half but at least two cases. When all members of the research team agreed on the final wording of themes, the CQR process was complete.

The ability to trust findings is imperative to advancement of the field and to the application of conclusions that influence lives. While referencing validity, Merriam (2009) asks, “[Are] the study's findings sufficiently authentic...that I may trust myself in acting on their implications? More to the point, would I feel sufficiently secure about these findings to construct social policy or legislation based on them?” (p. 210). Social scientists must provide the reader ample detail to demonstrate reasonable conclusions (Merriam, 2009). With all of these elements in place, including the CQR process itself, conducting a trustworthy study was attainable. 


\section{Chapter IV: Findings}

Five domains emerged from the data: perception of psychological empowerment, perception of social empowerment, perception of physical empowerment, perception of biggest messages, and experience of program. The cross-analysis procedure confirmed the domains and categories and their frequencies (i.e., general, typical, and variant). A summary of the domains, categories, and core ideas is available in Table 1. 


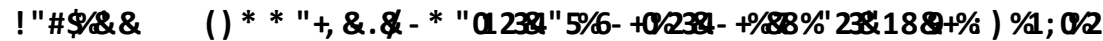

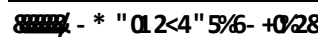
$\boldsymbol{\&}$

\section{Domain 1: Perception of Psychological Empowerment}

a) Increased Positive Self-Construct increased ability to be yourself and love yourself; increased levels of feeling wanted, confident, valuable, and worthy; increased feelings of self-respect, self-control, and the courage to be in control of their lives

b) Increased Conscious and Mature

\section{Decision-Making}

c) Reinforced Psychological Skills and Strategies

d) Impact on Sport Performance increased desire to do the "right thing"; to prioritize safety and wellness in all environments; to watch out for others; to intervene when able; to be responsible with alcohol; to be aware of sexual assault; and to make schoolwork a priority; heightened awareness

reinforced mental skills and strategies of goal setting, positive self talk, mental strength, focus, imagery, and resiliency

contributed to getting more sleep and reducing alcohol consumption
General

Typical

Typical

Typical

developed overall perspective, solidified expectation to act as a representativ of the University and athletic department, to set a good example of and for your team, to use the student-athlete platform for good, and to reach athletic performance standards

b) Role Modeling d) Building Relationships

e) Resisting Peer-Pressure increased desires to positively influence teammates, FSA, and community members; and increased perception of staff as role-models

increased quality and frequency of communication between teammates, FSA coaches, and staff; decreased cliques; decreased negative judgments and assumptions of others; and prompted hallway conversations increased friendship-building; cultivated positive relationships between teammates, FSA, and staff

increased ability to overcome desires to fit in; to accept and engage in behavior outside norms; and to resist pressure to consume alcohol

\section{erment}

increased positive body image and acceptance of physical self

increased pride in athletic bodies and embraced tomboy stereotype

expanded definition of female athlete and scope of femininity
General

General

General

Variant

Variant

Variant

Variant

c) Widening Definition of "Female Athlete"

Domain 4: Perception of Biggest Takeaways

a) Be Yourself

b) Help Others

c) You're Not Alone

d) Be Careful

Domain 5: Experience of Program

a) From Initial Resistance to Acceptance

b) Dealing with Relationships

c) Talking to Teammates About Program

d) Using Small Groups be yourself, be the best version of you, give your best effort, speak up, stand up, and use your voice

do what's right, help other people, look out for others, have each other's back, and opened up to others, decreased cliques and decreased judgment of other women

increased feelings of support and helps them know they're not alone

always have others around you, avoid bad situations, be cautious of your actions, and don't be somewhere by yourself
General

Variant

Variant

Variant

initial resistance to attendance, perceived lack of time due to other

General responsibilities, and almost "cheesy positive," but found value in messages once present wants more on other types of romantic relationships

Variant increased general conversation with teammates

Typical

enjoyed small group conversations, facilitated growth through uncomfortable conversations, learned from others' stories

Typical

Note. General (all or all but 1 of the cases); Typical (more than half of the cases); Variant (half of the cases or less). 


\section{Perception of Psychological Empowerment.}

The first domain, perception of psychological empowerment, embodied the changes in assessment of self that resulted from participation in the social responsibility educational intervention. Positive self-construct, the first category within psychological empowerment, most notably included increases in self-acceptance and self-esteem. Although many factors shape the thoughts individuals have of themselves, participants specifically cited increases in the ability to be yourself and love yourself; in feeling wanted, confident, valuable, and worthy; in increased feelings of self-respect, and in increased feelings of self-control and the courage to be in control of their lives. These feelings of acceptance are illustrated in Keke's conclusion of:

In [the meetings], hearing those messages of it's okay to be confident, it's okay to do this...It just makes you feel more comfortable and realizing that it's actually cool to be confident...So I think [it] just encouraged me and reinforced those values of be who you are and love yourself, and then others will love you for loving you.

Also central to the category of positive self-construct were participants' descriptions of feeling worthy, which is illustrated in Jenna's statement:

[The program] reinforces the importance of a woman's worth. And it's not just because we are female that are we worthy. But it's because we are human, and we deserve that respect. And we should not be disrespected or mistreated under any circumstance, and that is just something that I think girls lose sight of, and [it] I guess shows you that you are more than the world makes you seem sometimes. 
Anna also describes her experience in this way and states, "I mean [it] challenges us to be more than... what people assume you are." Altogether, increased positive self-construct represents the participants' increases in self-regard after experiencing in the social responsibility program.

Increased conscious and mature decision-making, the second category within perception of psychological empowerment, represented increases in the desire to "do the right thing," prioritizing safety and wellness, "having each other's back," responsibility with alcohol, and awareness of sexual assault. Although this category extends to multiple settings, Grace's experiences illustrate the importance of decision-making when others are in difficult situations:

I can remember times where I have seen teammates do those things and did nothing because it you don't really know how to react in that situation until you're in that situation but [the program] brings it that you really should stand up and [say], 'don't do this type of thing'... It gives you a chance to say, 'okay well I don't really know [for example] the basketball team, but I know them well enough to know if they need to get out of this situation.

Crena also emphasized the importance of taking action and stated, "If you know something isn't right, don't just let it keep happening. Do something about it." Grace and Crena's statements highlight the importance of taking action and relate to the value of bystander intervention.

Reinforced psychological skills and strategies, the third category within psychological empowerment, represented increases in mental skills and included goal setting, positive self talk, mental strength, focus, imagery, and resiliency. For example, a 
letter-to-self activity helped reinforce goal setting with Michelle. She stated, "I read that note at the end, and I had stuck to my goals and stuck to what I wanted to do. So it helped me kind of keep track even though I didn't have that letter the whole time." Crena also stated that she "mentally got stronger in a way."

In addition, the development of psychological skills and strategies influenced other environments, and as Crena illustrates, imagery influences her decision-making process:

I kind of play a little video in my mind or act it out in my mind, and if I say yes to this decision...then I'll just go with the benefits, and if I say no...I know I'm not going to do that. So I just like act it out in my mind first before I act on it.

Rose also describes the influence of psychological skills and strategies on her decisionmaking:

[The program has] helped me think more. I rarely think before I do things. I'm a very impulsive person, and its helped me become less impulsive, to stop and think about things because I always talk before I speak or talk before I think, and it's gotten a little better now. I've noticed it.

Furthermore, Rose describes the development of focus:

It taught me a little bit how to not stress so much and to focus on what's happening now and what I can do to make whatever is going on better...I don't know what's going to happen, so I just need to focus on what's going on in the moment and how to face things right then.

Altogether, participants described the reinforcement of psychological skills and strategies that influenced a variety of environments. These skills also specifically related to the 
categories of positive self-construct and increased conscious and mature decisionmaking.

Impact on sport performance, the fourth and final category within psychological empowerment, most notably included behavior regulation of sleep and alcohol consumption. Michelle described her experiences and stated, "I would pick going out over studying or going out over just getting more sleep when I needed to sleep...I think I've really been able to move on." She also stated:

There were less parties, so I got used to staying home. And I didn't have the urge I guess to drink, and I didn't want to drink because then I did notice that like [my sport] was being like easier and I was getting better. [So] whenever I had an opportunity to drink, I'll be like 'oh well I don't know like, do I really want to?' because it was going to make my [practice] on Monday harder.

Furthermore, Rose described regulating her alcohol consumption after experiencing a segment of the social responsibility educational intervention:

I also the remember the time where we had clickers and they asked us like how many of you guys drink throughout the week or how many days...I was thinking in my head, I was like that's kind of a lot. So after that it kind of went down a little bit. I kind of was more conscious about how much I was drinking and how much I was partying and how it could make me better if I didn't do it that much. It's okay to have a good time every once in a while but not every day of the week. Altogether, participants described the regulation of behavior that influenced sport performance. Collectively, perception of physical empowerment represented the increases in the assessment of self that contributed to mature decision-making. 


\section{Perception of Social Empowerment.}

The second domain, perception of social empowerment, embodied the relationships between student-athletes and staff and the sense of connectedness built within the department as a result of participation in the social responsibility educational intervention.

Big picture and reputation, the first category within perception of social empowerment, represented the development of perspectives, expectations to reflect university and department values through behavior, and expectations to reach athletic performance standards. Participants largely described this category as the outward portrayals individuals bring to environments. KeKe captured the essence of these representations when she stated, "I think it just reminds everyone of the kind of image we want [our school], female athletes to be like, and we want to help everyone grow in the right direction." In addition, participants described the expectations related to athletic performance. Grace stated:

If you want to have a good name from your university, you have to have good people, and you always leave [the program] feeling better. So...like, damn, here it is. Like, feel good about it, be a part of it, we want you here, but at the same time get your job done.

Furthermore, participants described an increased responsibility to use the student-athlete platform for good, and Anna illustrated this when she stated:

I'd like to think that it's made me a better leader for not just my teammates but classmates and friends that aren't athletes and recognizing the impact we can have. I've become better about using my platform as a student-athlete to impact 
people not associated with sports, because the athletic department has opened a lot of doors for me and [the program] shows you that if you use it properly, you can use it to your advantage to help more than just yourself.

Role modeling, the second category within perception of social empowerment, represented increased desires to influence others and developed the perceptions of staff. For example, KeKe stated:

Especially when they're like taught by the people who you look up to...like we see those confident people, and we're like oh, I want to hear what you have to say about how we should do things, because obviously it worked for you.

Participants also described these interactions as a relational experience. For example, KeKe stated, "It's also cool with [the program] how we get to see sometimes a vulnerable side of someone we don't normally do. I remember with [one of the staff members] she worked with us, and we saw [a much different] side."

Increased communication, the third category within perception of social empowerment, represented increases in the frequency of interactions, in positive opinions of others, and in decreases in cliques. Keke's experience captured the essence of this category, and she stated, “I remember there was one girl who I didn't really know and...looked kind of mean. But whenever we got in our groups, she was a really sweet person and genuine and down to earth." Although the elements of communication also touch on other categories, facilitating greater camaraderie, as Rose illustrates, served as the fundamental core idea:

I think that we all get along better...We're not all best friends, but I think it's helped definitely with people that you're acquaintances with. Sometimes you just 
kind of walk by and people actually say hi to each other now. Like oh we were in the same group or we were at the same this, and it definitely helped with the interaction just around the [facilities].

These types of interactions influenced the nature of communication between the female student-athletes, and as KeKe adds, can have a larger influence on decreasing cliques:

When we all got together with different sports, I think that broke up a lot of like negative images of other girls in our mind. If one of my teammates were in another group with some other girl, she would be like oh, she actually was like a really nice person. Like she is really cool, and I guess whenever she tells a team that, it changes the image to all of us of what we think of her.

Participants also described increased levels of respect for others after engaging in meaningful conversations. Anna stated, "The respect you gain for them...is part of how you see them, so even if you don't discuss it or consciously acknowledge it, it shapes the way you view other people." Still, the judgment of other women is problematic, but as Keke illustrated, replacing those thoughts with others is possible:

Naturally we just judge everyone around us. But when you think about it, I don't want to be judged, so why would you judge other girls? And every girl says they hate drama and they hate mean girls. But then you're enforcing it. It doesn't make sense. So that's kind of something that's stuck in my head after the meetings, like the next day in the dining hall, I'm not trying to like look at girls and whisper. Instead, let me think of other things, maybe like being a better leader on the team.

Altogether, participants described increased communication as the positive conclusions 
about other female student-athletes based on conversations that led to a more open approaches and attitudes toward each other.

Building relationships, the fourth category within perception of social empowerment, highlighted new connections between female student-athletes and other female student-athletes and between female student-athletes and staff. Participants most notably cited increases in friendship building as Anna described:

I know for a fact that I've met other female athletes purely through [the program]. I'm not going to meet them being in [my sport]. We have different schedules. We're not in the dining hall at the same time. So without some forced interaction we wouldn't meet these people.

Crena also described a similar experience and met her best friend, who happens to play a different sport than she does, during the social responsibility educational interventions. Crena stated, "[She] is my best friend, so I go to her for everything. If I'm like upset, I go to her. She is the first person I talk to." In addition, Anna found commonality with others and described building friendships as, "understanding that even if we play different sports, we all had similar struggles. And that's an easy way to make a friend, just to figure out that you are both going to the same thing and you can joke about it or talk about it." Increasing friendships is a necessary component of feeling connected and as Keke stated, helps expand student-athlete experiences:

I feel like since we started it, we've branched out more. Like I have one of my really good friends on [one] team and one of my other good friends on [another] team... So I guess just seeing and not feeling closed into the group that you're supposed to be in. It's just making friends regardless of what the social norms are. 
Furthermore, participants described a sense of community that resulted from the social responsibility educational interventions. Lucy describes it in this way:

Having the smaller community within the bigger community helps a lot. And again just being able to connect with the other female athletes. I don't think I would have [made friends] if it wasn't for [the program] and having that smaller environment.

Altogether, participants described building relationships as the feelings of unity and togetherness that resulted from increased friendship with teammates and student-athletes on different teams.

Resisting peer pressure, the fifth and final category within perception of social empowerment, represented the ability to overcome desires to fit in, which primarily focused on alcohol consumption. Lucy's experience with the program illustrated this influence:

It gives you backup information if you're having trouble making a choice, so you can think about, 'oh like, this alcohol, like this is my body or whatever.' Then it makes it easier like, no I don't drink when people are peer pressuring you in doing it. And then thinking about all the side effects, like what it does to you...so I think that helps you a lot because you'd feel like 'oh I'm not being the cool one' or whatever, but then you have that information to backup...so it makes you feel better about your choice of not drinking or whatever and going along with peers. That helped a lot.

Grace's experience also illustrated resisting pressure associated with alcohol consumption and states, "You don't have to be a part of that. If you don't want to be 
drunk, don't do it. And I feel like [it] helps you [know]...like there's more people like me that doesn't want to do it, so why do I need to do it?" This category also relates to the increased conscious and mature decision-making and contributed to the social elements of the empowerment process. Collectively, the perception of social empowerment displayed increases in individual perspectives, communication, and friendships.

\section{Perception of Physical Empowerment.}

The third domain, perception of physical empowerment, included categories that touch on an expanding definition of female athlete and femininity, embracing tomboy stereotypes, taking pride in athletic bodies, and increasing positive body image. Although many factors contribute to these findings, Lucy captures the essence of this domain and stated, "We can have that appearance of being strong women. We don't have to be little delicate females." One of the most commonly cited examples of expanding the definition of female athlete was embracing stereotypes that typically hinder the full expression of self. Rose described a conversation about overcoming these stereotypes:

I think it was the very first meeting we had where [people in my group] were talking about how they wished that certain things, like you don't have to super girly to be a girl or they were talking about how she likes to go hunting... or that people are like 'oh, that's a guy thing.' She's like, 'no I can be pretty and be a girl and go hunting.'

Similarly, Anna added to the understanding of female athlete and illustrated increased pride in athletic bodies:

We are more muscular females than the average girl, and so while I'm still not like $100 \%$ okay with how big my arms are because we weight lift, I'm more okay 
about it. I kind of brag about it when I'm with my friends joking around rather than being self-conscious about it.

Rose's experience also contributes to the expanding definition of female athlete and positive body image. She described the influence the social responsibility educational intervention had on what she values:

After we had like those meetings about muscular doesn't mean fat, it's not a bad thing... and after getting my surgery and having all those meetings, that really made me appreciate like 'oh like I wish I still had those muscles that I used to have before my surgery.' It's helped me just ignore that kind of stuff. It's helped me ignore physical appearance over mental health and like how my body actually feels instead of like how it looks.

As their experiences reveal, expanding conceptualizations of femininity and increasing pride in their physical bodies contributed to greater self-acceptance. Still, as Rose illustrated, creating a positive body image is challenging for many. She stated, "I know some of the [athletes] on our team want to be super skinny and not muscular...As much as people don't want to admit it, there are a lot of people that have issues with it." Altogether, participants described the perception of physical empowerment as embracing stereotypes, accepting their athletic bodies, and improving their body image.

\section{Perception of Biggest Takeaways.}

The first category within perception of biggest takeaways, "be yourself," related to the participants' abilities to stand up and speak up for themselves and in increased desires to give their best efforts. For example, Crena stated, "[It] helps you to have a voice. And it's like taught me how to make yourself be known, and then, to have your 
voice be heard." Furthermore, Grace emphasized the drive to increase individual efforts and stated, "Just the fact that [it's] all about empowering yourself...empowering your self-esteem. I feel like...the environment just makes you want to be stronger as an individual." Altogether, participants described the category of "be yourself" as their increased awareness and comfort to share their true selves.

Helping others, the second category within the domain of perception of biggest messages, related to the desire to help and open up to others. For example, Crena stated, "When we...went into the real places and stuff, they're like ask a couple of stuff, open up a little bit. I would tell like the little bits and pieces, but then I like opened up completely." Participants also described increased desires to watch out for their teammates and friends.

You're not alone, the third category within perception of biggest messages, represents of relationships and connectedness that results from participation in the social responsibility educational intervention. Grace described these feelings of support from student-athletes and staff as:

Knowing that they're going through the same experiences as you and that they have been there...you don't have to be embarrassed of what happened or what didn't happen or what you should have done or what you could have done. It's like you have people that's made those same mistakes that so it just makes you feel like you're not alone.

Jenna described this support through connection with the staff on difficult and challenging situations:

[Bad things] happen a lot, and we just brush it off, but when somebody else says 
that, you are just like I'm not alone this scenario. It's kind of like you can relate more, like these women are actually trying to help me.

The final category of "be careful," within perception of biggest messages, related to avoidance behavior and touched on elements of caution and fear. For example, Grace illustrated the influence of the program on her approach with alcohol:

[Staff members'] personal experiences make you think, 'wow, should I really do that'?...Like wow that could happen to me. Do I really want to get so drunk that that happens to me, you know? I feel like the [the program] helps you kind of see that you don't have to be like that image that everyone thinks.

Michelle's experiences with the program also illustrated increased awareness of sexual assault and resulting caution:

I know that when we talk about the red dot thing [related to sexual assault and violence], those kinds of things like made me think twice about, like being more responsible in making those decisions in my head. I don't want to be put in a situation like that, so I stay out of it. I stay away from that.

Altogether, participants described being careful as their increased attention to avoiding potentially harmful situations, regardless of the environment.

\section{Experience of Program.}

The fifth and final domain, experience of program, embodied the elements and components of the sessions themselves that influenced participants in a variety of ways. From initial resistance to acceptance, the first category within experience of program, encompassed the preliminary hesitations from participants to attend the sessions but the 
sense that they valued the messages once present. Rose's description illustrated this notion:

At first nobody wants to go to these things, and it's kind of hard to get people into it, but I think once you get into it, it really does help. It just takes a little bit for everyone to want to come and like get used to it and want to talk about things. In addition, student-athletes have many responsibilities involved with their participation in intercollegiate athletics, and as Jenna illustrated, balancing them with personal development opportunities such as the social responsibility educational interventions is challenging:

It's not a burden that we have these meetings, it's just we feel like our main focus shouldn't be on development. It should be, well I have homework, or I have an exam tomorrow, and that you may think of those as much more important.

Still, although the participants described a sense of resistance from teammates based on time constraints, they found value in the messaging once in attendance.

Jenna captured the essence of this feeling and stated, "We kind of need a refresher as often as we do with [the program] because it puts things in perspective again...It's a reality check." Her additional description illustrated this type of thinking:

'We know everything' is basically what our mentality is. We feel like we don't need to know anything more than [what presenters are] telling us, I guess. That sounds pretty bad, but we just feel like we know everything, and so when we come to these meetings, it's just like, we know this, we know this, but there are other times like we really don't know this, and it's just like a reality check for everyone. 
In addition, participants described consistent and reinforced messages as beneficial. KeKe illustrated their importance and connection to developing a positive self-construct:

Hearing those messages that like its okay just to accept who you are...I think it has helped a lot of the girls in our team. I know it often just helped ease their mind a little more because we just need those reminders, like always constant reminders, because we forget that we're supposed to love ourselves and we're not supposed to be perfect.

Altogether, from initial resistance to acceptance revealed the lack of awareness prevalent among the female student-athletes, and as Jenna described, verbal persuasion is valuable. "Women need to be told that they are worthy. They to need hear it," she said.

Talking to teammates, the second category within experience of program, represented the additional conversations about the social responsibility educational intervention between female student-athletes after the program ends. Participants described applying their experience to help teammates transition to the college environment. Michelle stated:

Our team has talked, and we said that we don't want the freshmen to have a freshmen-learning year. We want to try to guide them, so from what we learned from [the program] and from our own years, we want to really just inform them and let them know. I mean they're going to make a decision regardless, but hopefully we can help them out and tell them things that we know and learned so that they don't have to go through it also.

Using small groups, the third and final category within experience of program, 
represented the growth gained through conversations with others. And although participants described them as awkward at times, as KeKe illustrated, small group discussions provided an avenue for development:

We're supposed to hear awkward things that make you feel uncomfortable. They're awkward because they're hitting home for you. So that's why I like whenever we talk about the thing that no one wants to talk about. You have to talk about it...to really get something out of it.

Collectively, the results of participants' experiences of the social responsibility educational intervention revealed valuable and noteworthy distinctions. Perception of psychological empowerment revealed the influence of the program on the assessment of self and the effects of decision-making. Perception of social empowerment revealed the influence on communication, friendship, and the meaning of set expectations. Perception of physical empowerment related to the acceptance of physical selves even if that fell outside traditional understandings of womanhood. Perception of biggest messages served as the takeaway messages and again touched on self-acceptance, support, and helping others. Finally, experience of program reveals the initial resistance but the resulting enjoyment and value once present. These findings serve as a valuable resource to those seeking to empower female student-athletes and provide insight into women's development in college. 


\section{Chapter V: Implications}

This study provided insight into understanding the influence of social responsibility educational interventions on the empowerment of female student-athletes. The five domains of perception of psychological empowerment, perception of social empowerment, perception of physical empowerment, perception of biggest messages, and experience of program fit directly within the conceptual framework. Understanding the findings in a way that aligns with Nikkhah, Redzuan, \& Abu-Samah's (2012) psychological empowerment, interactional empowerment, and community empowerment provides further insight into the development process.

\section{Psychological Empowerment.}

Building a positive self-construct and developing self-awareness were central to the student-athletes' experiences with the program and included elements selfacceptance, self-esteem, self-regulation, and intrinsic motivation. Increasing the ability of individuals to view themselves in a positive light regardless of circumstances (e.g. love yourself, you are worthy) brings them closer to unconditional self-worth, which is highlighted in psychological well-being literature and mindfulness literature as contributing to increased levels of happiness, lower risks for depression, lower levels of downward social comparison, and lower levels of emotional difficulties (Chamberlain \& Haga, 2001; Carson \& Langer, 2006).

Participants in the study also described increased feelings of self-control and the courage to be in control of their lives, which research has shown to contribute to higher grade point averages, better overall adjustment, less binge eating and alcohol abuse, better relationships and personal skills, more secure attachments, and more optimal 
emotional responses (Tangney, Baumeister, \& Boone, 2008), among others. The benefits of developing positive assessments of self for women, and in particular for female student-athletes, is evident.

In addition, developing self-awareness (e.g. stand up and speak up for yourself) has been highlighted in counseling psychology literature as a foundational competency to promote the academic, career, personal, and social success of individuals, especially for students of color and for those with learning disabilities (Astramovich \& Harris, 2007). These findings support validate the need to provide personal and identity development opportunities during their college experience. Development for female student-athletes in particular becomes beneficial because of the additional athletic performance stressors on student-athletes. Providing an opportunity for female student-athletes to feel good about themselves simply for who they are, regardless of their athletic or academic performance, seems to contribute to increases in an overall evaluation of self and their abilities to advocate for themselves.

Female student-athletes in this study also described the development of psychological skills and strategies that included goal setting, positive self-talk, mental strength, focus, imagery and resiliency. The benefits of developing these skills are abundant in sport psychology literature and among others, include increased athletic and academic performance (Aoyagi \& Portenga, 2012). Related to empowerment, developing psychological skills and strategies overlap with interactional empowerment and provide advantages during the decision-making process and with resistance to peer pressure. Participants described the application of psychological skills and strategies in a variety of settings including greater responsibility with alcohol, prioritizing safety, and 
performance-driven decision-making. Therefore, incorporating psychological skills into programs aimed at empowering female student-athletes seems advantageous. Participants described the social responsibility educational interventions as directly contributing to fundamental aspects of psychological empowerment that center on the internal, psychoemotional factors that influence self-assessment.

\section{Interactional Empowerment.}

Some of the most visible outcomes from the female student-athletes' experiences with the social responsibility educational intervention were those related to interactional empowerment and most notably include "having each others' back," engaging in bystander intervention, and resisting pressure to consume alcohol. Research on bystander intervention highlights the prevalence of crimes against women and validates the need to educate students on effective methods to intervene during challenging situations (Coker et.al, 2011, Foubert et. al, 2010). Providing an opportunity for female student-athletes to develop their decision-making skills and bringing awareness to topics that can influence them seems to increase their ability to intervene during challenging situations. And based on the 2008 National Crime Victimization Survey, 75 percent of the women who reported a rape were less than 25 years old, so the importance of creating the desire for female student-athletes to watch out for each other seemingly cannot be overemphasized as an element of any program curriculum aimed at empowerment.

However, a member of the research team concluded that some of the participants' experiences of the social responsibility educational intervention touched on elements of caution and fear. This type of avoidance behavior was described in the context of potentially harmful situations that women in particular should avoid (i.e. "don't walk 
alone at night"), which contributes to a culture of fear (McKibbin \& Shackelford, 2013; Pritchard, Jordan, \& Wilcox, 2012) that can inhibit women's empowerment. This dilemma of providing appropriate awareness to real concerns that affect women while simultaneously empowering them to live their best lives free of restraint is challenging to overcome.

However, literature related to educational programming for campus safety suggests that although focusing research on student experiences is noteworthy, training faculty, staff, and administrators on how norms and policies shape the college environment is also important (Baynard, 2014). Using campus resources, specifically including women's centers and relationship and sexual violence prevention centers, should be considered when developing a program aimed at empowerment because of the weight of the dilemma.

In addition, female student-athletes also provided insight into their experiences with resisting peer pressure, most often related to alcohol consumption. Participants described a variety of ways their views on alcohol shifted, many specifically citing the desires to influence athletic performance and to set a good example for others. No matter the reason, reducing alcohol consumption on college campuses is a beneficial outcome considering that research indicates the problematic nature of alcohol in a variety of settings including coercive sexual experiences (Palmer et. al, 2010), group drinking norms (Neighbors et. al, 2010), brain development (Parada et. at, 2011), and eating disorders (Wilsnack, S. C \& Wilsnack, R. W., 2014) among others. Still, because alcohol consumption is problematic on nearly every college campus, discussing and determining individual responsibility and team standards for behavior related to alcohol is needed. 
Further research specifically examining the relationship between educational programming and specific behavior change related to alcohol may provide greater understanding in this area. Nonetheless, increased awareness and attention to social responsibility topics seems to have some influence on female student-athletes' ability to resist peer pressure, specifically with alcohol consumption.

Furthermore, female student-athletes described expanding the definition of femininity, which most notably included increases in positive body image and overcoming masculine stereotypes. These findings suggest that education, awareness, and honest conversations about self-acceptance and gender performance can help female student-athletes take pride in their sport bodies and can help them overcome typical assumptions related female athleticism. However, research reveals that 6-45 percent of female athletes have engaged in disordered eating at some point in their life (BratlandSanda \& Sundgot-Borgen, 2012) and that college women perceive their ideal figures as thinner and less muscular than their current figure (Grossbard, Neighbors, \& Larimer, 2011). Therefore, more attention to this topic is needed.

Taken together, bringing awareness to topics that influence female student-athlete lives and educating them on how to make good decisions, although not necessarily which decisions to make, seems beneficial for them and their ability to act upon their environment. Nonetheless, compared to the spirit of interactional empowerment, participants described the social responsibility educational interventions as contributing to many aspects of the domain that center on the ability to take action, but more research examining actual behavior change is needed. 


\section{Community Empowerment.}

Increasing feelings of community were also central to female student-athlete experiences with the social responsibility educational intervention, which included cultivating friendships, increasing feelings of support, and decreasing cliques. These outcomes reflect literature on college student development that reveals students perform better academically and are more satisfied when they, among others, have good relationships with peers and administrative staff (Kuh, Kinzie, \& Schuh, 2005)

In addition, research on group behavior and bystander intervention reveals that individuals are more likely to help others who are viewed as in-group members and not out-group members (Levine, Cassidy, Brazier, \& Reicher, 2002) which displays the importance of creating unity within an athletic department. Adding to this sense of unity, participants described viewing the professional staff as role models based on the highly personal stories shared, which makes it an important component of creating connections with female student-athletes, particularly within the context of personal development.

In addition, the depth of information shared during the interviews and the emotion behind their experiences made it seem that the participants wanted and appreciated having someone to talk to. Program developers and athletic department staff should pay particular attention to the types of interactions and conversations with student-athletes because of the value associated with personal connections. Altogether, providing opportunities for female student-athletes to connect with other student-athletes and staff through meaningful experiences seems to bring a sense of unity to the department and feelings of support to the students. Future research should consider examining these types of relationships in different contexts. 
Furthermore, female student-athletes in this study described layers of responsibility during their experience, which most notably include representing the team, department, and University in an upstanding manner. Evidence of this responsibility ranged from emphasis on volunteerism and meeting athletic performance standards to setting good examples for others through behavior outside the athletic arena. Gaining this larger understanding also seemed to contribute to a greater likelihood of perspective taking and to understand the larger meaning of their behavior. Therefore, providing clear standards on a variety of topics to female student-athletes seems advantageous for athletic departments that want to build unity around common objectives.

Participants also described an attachment to their sports that revealed love, passion, and dedication. Honoring the value female student-athletes place on the performance in their sport seems as if it would contribute to their development during the college experience. Compared to the spirit of community empowerment, participants described the social responsibility educational interventions as contributing to unity and connectedness more than group action, so more research is needed to examine group behavior change.

Overcoming initial resistance and perceived redundancy were also central to the female student-athletes' experiences with the program and included elements of a lack of time, lack of awareness, and "reality checks." Although participants described their attendance at meetings through external motivation (e.g. mandatory presence, food and tshirts), once there, they also described gaining internal rewards (e.g. found value in messages once present, reminders were needed). Research on student-athlete well-being indicates a need for athletic department staff to be mindful of their development, 
particularly in relation to mental health (Gill, 2008; Austin \& Austin 2014), but research on college student development also calls for greater attention and awareness to important topics including diversity (Loes, Salisbury, \& Pascarella, 2013) and healthy relationships (DeVito, 2012), which are challenging to truly instill. Still, providing some sort of external incentive to create excitement and then providing valuable and meaningful content seems important for program delivery.

In addition, although many participants described the environment as overwhelmingly positive, one participant in particular described it as a "short-lived high on team spirit." Although maintaining a high level of energy and attention toward every topic covered is challenging, program developers and athletic staff should make every effort to incorporate elements of lessons into the larger departmental culture.

Furthermore, participants indicated a greater benefit to freshman and sophomore student-athletes than to junior and senior student-athletes based on the transitional advantages associated with entering the college environment. Female student-athletes in this study also described gaining insight and knowledge through small group, and sometimes uncomfortable, discussions. Altogether, these findings seem to indicate that even though female student-athletes may feel like they already know and understand the type of information presented, reminders are valuable and appreciated. Their experiences also indicated that more targeted programming for first and second-year student-athletes could provide greater transitional benefits. And although participants described instances when they did not find meaning with a particular topic or component presented, they all described a connection to elements of the programs. Therefore, including a diverse range 
of topics to reflect the diversity of the female student-athlete population should be considered.

As a whole, participants described advantages of the social responsibility educational intervention in a variety of ways that contributed to substantial changes and benefits in their lives. Findings also reveal that female student-athletes are likely to be receptive to information and awareness provided to them in similar settings. Still, because the hurdles to truly empowering women are so great and the extent to which the intervention truly empowered the women is not explicitly clear, more research is needed. Nonetheless, based on the findings, this type of programming during the student-athlete experience can serve as a step in the right direction.

\section{Limitations}

Still, this study is not without limitations. For example, as a member of the group that developed the social responsibility educational intervention and assisted with program delivery, the potential influence of socially desirable responses should be taken into consideration. The primary researcher also conducted the interviews. This step could again bring socially desirable responses, but could also reveal a greater depth of knowledge based on strong rapport with the participants. Although every measure to reduce social desirability was taken, findings should be understood with this knowledge in mind.

Additionally, data for this study was collected from female student-athletes representing different sports at one institution where sport psychology services were integrated throughout the department and were readily available to student-athletes. Therefore, findings may be influenced by the unique environment created within this 
particular athletic department. Because the effectiveness of a social responsibility educational intervention may be different at institutions that do not have integrated sport psychology services, taking an in-depth look at a social responsibility educational intervention at other institutions may help athletic department leaders gain insight into program development when attempting to educate and empower female student-athletes. Future research should investigate the effectiveness of such a program in a variety of institutional settings, including but not limited to those that differ in terms of geographic location, institutional size, religious affiliation, and athletic division status to determine if differences exist.

In addition, a sample size of at least eight participants is recommended with CQR methodology (Hill et al., 2005), and the current sample included exactly eight female student-athletes from different sport teams, with different ages, and with different ethnic and racial backgrounds. Specifically the study included female student-athletes aged 1923, two of which were on team sports and six of which were involved in individual sports. In addition, of the eight women, five are Caucasian, one is African-American, and one is part Hispanic.

Furthermore, at the time of the interviews, three of the women were freshmen, one was a sophomore, two were juniors, and two were in their fourth or fifth years. The categories that emerged from these participants' experiences were consistent across half (variant), more than half (typical), or all (general) cases, and thus, may be considered descriptive of the overall sample. Nonetheless, future research should consider including a more homogeneous sample (e.g., all freshmen and sophomore female student-athletes, all female student-athletes from team sports or individual sports) and possibly comparing 
samples for differences in their experiences of a social responsibility educational intervention.

Findings of the current study also indicated that participating in the social responsibility educational intervention is a multidimensional experience and that understanding the student-athlete experience is complex. The current study revealed the importance of developing multiple types of empowerment for female student-athletes and creating an environment where this type of development is possible. However, findings reveal little focus on the development of empowerment through the lens of race and ethnicity, which highlights the need to incorporate these topics into programs. This lack of attention extends Hawkins' (2013) work on race and ethnicity in intercollegiate athletics and higher education, and therefore future researchers may want to consider focusing on these topics.

In addition, further research is needed to address the complexities associated with intersectionality, a concept that examines knowledge gained at the junction of race, class, and gender. Intersectionality helps explain how multiple identities interrelate (Crenshaw, 1991), which may be particularly relevant to developing empowerment in female studentathletes who come from variety of backgrounds. Furthermore, additional research on parallel programming for male student-athletes may provide insight into their experiences and could improve the interactions between all student-athletes within the intercollegiate athletics and higher education environment.

All together, the social responsibility educational interventions seem to have an overwhelmingly positive and important influence on the experience of empowerment for female student-athletes. Providing opportunities for students to develop into the best 
version of themselves while providing an environment full of support could dramatically change the student-athlete experience. Challenging them to consider new ideas, celebrating the beauty present in themselves and others, and connecting them with other female student-athletes and staff could make a substantial difference in their lives. Most importantly, empowering female student-athletes to believe in their authentic selves and providing them the tools to act upon those beliefs can alter the path of their lives for the better and, in a small way, can contribute to improved definitions of womanhood.

Social responsibility educational interventions are clearly a medium through which athletic department leaders can advance their efforts to empower female studentathletes through educational and personal development opportunities. This type of programming is not the answer to the challenges of the student-athlete experience, but they are certainly a place to begin to make improvements. 


\section{Work Cited}

Aoyagi, M. W. \& Portenga, S. T. (2012). Reflections and directions: The profession of sport psychology past, present, and future. Professional Psychology, 43(1), 32-38.

Astin, A. W. \& Antonio, A. L. (2012). Assessment for excellence: The philosophy and practice of assessment and evaluation in higher education. United Kingdom: Rowman \& Littlefield.

Astramovich, R. L. \& Harris, K. R. (2011). Promoting self-advocacy among minority students in school counseling. Journal of Counseling and Development. 85(3), 269-276. DOI: 10.1002/j.1556-6678.2007.tb00474.x

Austin, J. A. \& Austin, J. T. (2014). Counseling student-athletes: Implications for the counseling profession. University of Wyoming.

Bandura, A. (1995). Self-efficacy in changing societies. United Kingdom: Cambridge University Press.

Batliwala, S. (1993). Empowerment of women in south Asia: Concepts and practices. New Delhi: FAO-FFHC/AD.

Bradbury-Jones, C., Irvine, F., \& Sambrook, S. (2010). Empowerment of nursing students in clinical practice: Spheres of influence. Journal of Advanced Nursing. 66(9), 2061-2070. DOI: 10.1111/j.1365-2648.2010.05351.x

Bradbury-Jones, C., Sambrook, S., \& Irvine, F. (2007). The meaning of empowerment for nursing students: A critical incident study. Journal of Advanced Nursing. 59(4), 342-351. DOI: 10.1111/j.1365-2648.2007.04331.x 
Bratland-Sanda, S. \& Sundgot-Borgen, J. (2012). Eating disorders in athletes: Overview of prevalence, risk-factors, and recommendations for prevention and treatment. European Journal of Sport Science, 13(5).

Carson, S. H. \& Langer, E. J. (2006). Mindfulness and self-acceptance. Journal of Relational-Emotive and Cognitive-Behavior Therapy. 24(1). DOI: $10.1007 / \mathrm{s} 10942-006-0022-5$

Cattaneo, L. B. \& Chapman, A. R. (2010). The process of empowerment: A model for use in research and practice. American Psychologist. 65(7), 646-659. DOI: $10.1037 / \mathrm{a} 0018854$

Chamberlain, J. M. \& Haaga, D. A. F. (2001). Unconditional self-acceptance and psychological health. Journal of Relational-Emotive and Cognitive-Behavior Therapy. 19(3).

Coker, A. L., Cook-Craig, P. G., Williams, C. M., Fisher, B. S., Clear, E. R., Garcia, L. S., \& Hegge, L. M. (2011). Evaluation of green dot: An active bystander intervention to reduce sexual violence on college campuses. Violence Against Women, 17(6), 777-796.

Compton, W. C., \& Hoffman, E. (2013). Positive psychology: The science of happiness and flourishing ( $2^{\text {nd }}$ ed.); Belmont, CA: Wadsworth.

Conger, J. A. \& Kanungo, R. N. (1988). The empowerment process: Integrating theory and practice. Academy of Management Review. 13(3), 471-482.

Crenshaw, K. (1991). Intersectionality, identity politics, and violence against women of color. The Stanford Law Review. 1241-1299. 
Crouse, K. (2010, March 5). A sport recoils from a punch and its publicity. New York Times.

Daniels, E. A. (2009). Sex objects, athletes, and sexy athletes: How media representations of women athletes can impact adolescent girls and college women. Journal of Adolescent Research. 24(4), 399-422. DOI: 10.1177/0743558409336748

Deci, E. L. \& Ryan, R. M. (2012). Motivation, personality, and development within embedded social contexts: An overview of self-determination theory. The Oxford Handbook of Human Motivation. Oxford University Press.

DeVito, M (2012). Why do college students stay in unhealthy relationships and why are peers hesitant to intervene? Providence College.

Foster-Fishman, R. G., Salem, D. A., Chibnall, S., Legler, R., \& Yapchai, C. (1998). Empirical support for the critical assumptions of empowerment theory. American Journal of Community Psychology. 26(4), 507-536.

Foubert, J. D., Langhinrichsen-Rohling, J., Brasfield, H., \& Hill, B. (2010). Effects of a rape awareness program on college women: Increasing bystander efficacy and willingness to intervene. Journal of Community Psychology, 38(7), 813-827.

Freire, P. (1996). Pedagogy of the oppressed. Trans. M. Bergman Ramons. Harmondsworth: Penguin.

Gayles, J. G., Rockenbach, A. B., \& Davis, H. A. (2012). Civic responsibility and student-athletes: Validating a new conceptual model. The Journal of Higher Education. 83(4), 535-557.

Gill, E. L. J. (2008). Mental health in college athletics: It's time for social work to get in the game. Journal of Social Work, 53(1). 
Grossbard, J. R., Neighbors, C., \& Larimer, M. E. (2011). Perceived norms for thinness and muscularity among college students: What do men and women really want? Eating Behaviors, 12(3), 192-199.

Guido-DiBrito, F., \& Batchelor S. W. (1988). Developing leadership potential through student activities and organizations. In M. D. Sagaria (ed.), Empowering women: Leadership development strategies on campus. New Directions for Student Services. (44), 51-62. San Francisco, CA: Jossey-Bass.

Hargens, L. L., \& Long, J. S. (2002). Demographic Inertia and Women's Representation Among Faculty in Higher Education. The Journal of Higher Education. (73)4, 494-517. DOI: $10.1353 /$ jhe.2002.0037

Hawkins, B. (2013). The new plantation: Black athletes, college sports, and predominantly white NCAA institutions. Palgrave Macmillian.

Huang, J. H., Jacobs, D. F., \& Derevensky, J. L. (2009). Sexual risk-taking behaviors, gambling, and heavy drinking among U.S. college athletes. Archive of Sexual Behavior. (39) 706-713. DOI: 10.1007/s10508-009-9521-7

Hughes, R. (2009, November 10). Pulling attention with a yank of a ponytail. The New York Times.

Jacobellis v. Ohio, 1964, 378 US 184. United States Supreme Court.

Johns, M. L. (2013). Breaking the glass ceiling: Structural, cultural, and organizational barriers preventing women from achieving senior and executive positions. Perspectives of Health Information Management.

Kabeer, N. (1999). Resources, agency, achievements: Reflections on the measurement of women's empowerment. Development and Change. 30, 435-464. 
Kalantari, B. (2012). The influence of social values and childhood socialization on occupational gender segregation and wage disparity. Public Personnel Management. 41(2), 241-255.

Kezar, A. (2004). Obtaining integrity? Reviewing and Examining the Charter between Higher Education and Society. The Review of Higher Education. (27)4, 429-459. DOI:10.1353/rhe.2004.0013

Kuh, G. D., Kinzie, J., Schuh, J. H., \& Whitt, E. J. (2005). Student success in college: Creating conditions that matter. San Francisco, CA: John Wiley \& Sons.

Lawless, J. L. \& Fox, R. L. (2012). Men rule: The continued underrepresentation of women in U.S. politics. Women and Politics Institute. Washington, DC.

Levine, M., Cassidy, C., Brazier, G., \& Reicher, S. (2002) Self-categorization and bystander non-intervention: Two experimental studies. Journal of Applied Social Psychology, 32(7) 1452-1463.

Loes, C. N., Salisbury, M. H., \& Pascarella, E. T. (2013). Diversity experiences and attitudes toward literacy: Is there a link? The Journal of Higher Education, 84(6).

Lindgren, E. C., Patriksson, G, \& Fridlund, B. (2002). Empowering young female athletes through a self-strengthening programme: A qualitative analysis. European Physical Education Review. 8(3) 230-248. DOI: $10.1177 / 1356336 \times 020083004$

Martens, M. P., Dams-O’Connor, K., Duffy-Paiement, C., Gibson, J. T. (2006). Perceived alcohol use among friends and alcohol consumption among college athletes. Psychology of Addictive Behaviors. (20)2, 178-184. 
McKibben, M. F. \& Shackelford, T. K. (2013). Comment on "Reexamining individual differences in women's rape avoidance" by Snyder and Fessler (2012). Archives of Sexual Behavior, 42(1), 1-4.

Menon, U. (2013). Women, well-being, and the ethics of domesticity in an Odia Hindu temple town. DOI: 10.1007./978-81-322-0885-3_1.

Minkler, M., \& Cox, K. (1980). Creating critical consciousness in health: applications of Freire's philosophy and methods to the health care setting. International Journal of Health Services, 10(2), 311-322.

Myers, D. G. \& Deiner, G. (1995). Who is happy? Psychological Science. (6), 10-19.

Neighbors, C., LaBrie, J. W., Hummer, J. F., Lewis, M. A., Lee, C. M., Desai, S., Kilmer, J. R., \& Larimer, M. E. (2010). Group identification as a moderator of the relationship between perceived social norms and alcohol consumption. Psychology of Addictive Behaviors, 24(3), 522-528.

Nikkhah, H. A., Redzuan, M., \& Abu-Samah, A. (2012). Development of 'power within' among women: A road to empowerment. Canadian Center of Science and Education. 8(1), 39-46. DOI: 10.5539/ass.v8n1p39.

Palmer, R. S., McMahon, T. J., Rounsaville, B. J., \& Ball, S. A. (2010). Coercive sexual experience, protective behavioral strategies, alcohol expectancies, and consumption among male and female college students (2009). Journal of Interpersonal Violence, 25(9), 1563-1578.

Parada, M., Corral, M., Caamano-Isorna, F., Mota, N., Crego, A., Holguin, S. R., \& Cadaveira, F. (2011). Binge drinking and declarative memory in university students. Alcoholism: Clinical and experimental research, 35(8), 1475-1484. 
Pascarella, E. T., \& Terenzini, P. T. (2005). How college affects students: A third decade of research. San Francisco, CA: Jossey-Bass.

Peterson, N. A., Peterson, C. H., Agre, L., Christens, B. D., \& Morton, C. M. (2011). Measuring youth empowerment: Validation of a sociopolitical control scale for youth in an urban setting. Journal of Community Psychology. 39(5), 592-605.

Pritchard, A. J., Jordan, C. E., \& Wilcox, P. (2012). Safety concerns, fear and precautionary behavior among college women: An exploratory examination of two measures of residency. Security Journal. DOI: 10.1057/sj.2012.39

Rodwell, C. M. (1996). An analysis of the concept of empowerment. Journal of Advanced Nursing. 23, 305-313.

Spencer, G., Maxwell, C., \& Aggleton, P. (2008). What does 'empowerment' mean in school-based sex and relationships in education? Sex Education. 8(3), 345-356. DOI: $10.1080 / 14681810802218437$

Steinfelt, J. A., Zakrajsek, R., Carter, H., \& Steinfelt, M. C. (2011). Conformity to gender norms among female student-athletes: Implications for body image. Psychology of Men and Masculinity. 12(4), 401-416.

Tangney, J. P., Baumeister, R. F., \& Boone, A. L. (2008). High self-control predicts good adjustment, less pathology, better grades, and interpersonal success. Journal of Personality. 72(2), 271-324. DOI: 10.1111/j.0022-3506.2004.00263.x

Vaughn, S., Shumm, J. S., \& Sinagub, J. (1996). Focus group interviews in education and psychology. Thousand Oaks, CA: SAGE.

Ware, S. (2011). Game, set, match: Billie Jean King and the revolution in women's sports. Chapel Hill, NC: The University of North Carolina Press. 
Wechsler, H., Davenport, A. E., Dowdall, G. W., Grossman, S. J., \& Zanakos, S. I. (2010). Binge drinking, tobacco, and illicit drug use and involvement in college athletics. Journal of American College Health. 45(5), 195-200. DOI:

$10.1080 / 07448481.1997 .9936884$

Wilsnack, S. C. \& Wilsnack R. W. (2014). Focus on women and the costs of alcohol use. Alcohol Res. 35(2), 219-228. 


\section{Appendix A: Social responsibility educational interventions}

Intervention \#1.

The first social responsibility educational intervention occurred on Monday, October 17, 2011. Six women, three full-time staff members, one from the campus Relationship and Violence Prevention Center (RSVP Center) and three graduate assistants, served as the planning committee. During the one-hour session, each of the committee members presented on topics related to social responsibility, which included messages on the following: intentionality, self acceptance, respect, the department's pregnancy policy, using your voice, sexual assault, bystander intervention, and pride in self. Videos and personal stories related to the topics were also incorporated to ultimately celebrate them as female student-athletes and to encourage them to incorporate the messages into their lives.

At the end of the session, which was held in the dining hall facility, the female student-athletes received informational handouts related to the topics, contact information of the committee members, and sheets listed with campus resources. They were also presented with a v-neck t-shirt with the slogan "This is what a female athlete looks like" in the shape of a strong arm, which highlights the range of female athleticism. As the inaugural meeting of Women for Women, this intervention provided a strong foundation and overview of the program.

\section{Intervention \#2.}

The second social responsibility educational intervention occurred on Monday, April 9 2012. Again, a handful of full-time staff members and graduate-assistants served on the planning committee, including the representative from the RSVP Center. Because 
I was interning at the University of Georgia, I was not involved in any aspects of this specific session like the other four. With a focus more on the effects and influence of alcohol, this session included the following: understanding the REAL woman acronym (Respects all people, Especially herself, Always does the right thing, and Lives a life that matters), personal stories and self-disclosure from two staff members, clicker questions and conversations related to alcohol consumption, creation of a construction model, and a group activity where each student-athlete shared what a real woman means to her.

At the end of this session, which was again held in the dining hall, the female student-athletes received notebooks with the same "This is what a female athlete looks like" slogan. Overall, this session focused on self-respect through healthy decisions regarding alcohol consumption. Together, the first two interventions centered on the number of ways individuals can show respect, which is one of the University's core values. Each year, the interventions focus on a different University core value.

\section{Intervention \#3.}

The third social responsibility educational intervention occurred on Monday, September 17, 2012. Once again, a handful of full-time staff members and graduateassistants served on the planning committee, including the representative from the RSVP Center. This session focused on responsibility and included panelists of a senior woman administrator (SWA), a writer of a women's sports blog, and a campus representative from the LGBTQ Resource Center. The SWA discussed the responsibility to the past through stories related to her extensive experience working with Title IX and women's participation in intercollegiate athletics. The writer of the women's sports blog, along with a committee member, shared stories related to their time at the University of 
Nebraska and challenges of the student-athlete experience, specifically including stories related to missing the Olympic team and disagreements with teammates. The representative from the LGBTQ Resource Center shared experiences of finding the courage to be her authentic self and reveal her sexuality. After the panel concluded, a committee member presented on the responsibility to others while using positive psychology themes. She specifically challenged expectations that accompany the tomboy stereotype for women in athletics and encouraged them to nurture relationships, inspire passion, empower growth, emphasize gratitude, and build positive emotions.

At the end of this session, which was held in a lecture-style auditorium, the female student-athletes received a second version of a v-neck t-shirt with the slogan "This is what a female athlete looks like," which again highlights the range of female athleticism. On the back of the shirt was a pink flower that symbolizes strength with femininity, which mirrors the message from USA Olympian Alysia Montano. Overall this session focused on the responsibility each individual has to the past, present, and future. An abbreviated, make-up session for this specific intervention, although available to all female student-athletes, was held Sunday, October 28, 2012 in a smaller study area in the same facility.

\section{Intervention \#4.}

The fourth social responsibility educational intervention occurred on February 6 , 2013. Like in previous sessions, a handful of full-time staff members and graduateassistants served on the planning committee as well as campus representatives from the LGBTQ Resource Center and the RSVP center. This session highlighted the historical roots of women in athletics and encouraged the female student-athletes to take proactive 
steps toward leaving the legacy they desire.

Included in the session were the following: a 15-minute skit depicting the advancement of women in athletics at the specific institution from 1889 through present, which included a stunt by the committee members depicting a 1932 example of Danish gymnastics; a highlight video of the female student-athlete performances set to the song "Girl on Fire" by Alicia Keys, a 30-minute interactive jeopardy game based on the information presented, understanding of historical shifts of women in athletics nationally, and knowledge of sport facts related to each institutionally-sponsored sport; and time for the female student-athletes to write a letter to themselves about the type of legacy they wanted to leave. The letters were kept in a safe location and were handed back at the end of the fifth intervention.

At the end of this session, which was held in the same dining hall as before, they were asked to complete an open-ended, three-item questionnaire and then received a wristband with the line "W4W: What's your legacy?" Overall, this session reminded the female student-athletes of the developmental changes in women's athletics, educated them on the variety of sports sponsored by the department, and provided an environment where they could interact with members of all teams. The questionnaires reveal these types of prominent messages from the female student-athletes: "Women rock," "to remember where you've been so you can continue to make a positive contribution to where you are going," and "The biggest thing is not to take our opportunities for granted. We're the first generation that is growing up with this and we need to set the tone for future generations." 
Intervention \#5.

The fifth social responsibility educational intervention occurred on Tuesday, April 23, 2013. Like in previous sessions, a handful of full-time staff members and graduateassistants served on the planning committee as well as campus representatives from the LGBTQ Resource Center and the RSVP center. In addition, the director of compliance and SWA joined the planning committee.

As the final session of the academic year, this intervention centered on taking deliberate steps to leave a legacy through the year-long responsibility theme. The session proceeded as follows: the director of compliance shared her personal story, specifically relating to the challenges she experienced with her interracial marriage and alcohol consumption in college. Then, the female student-athletes formed smaller groups and received the letters they wrote during the fourth intervention. In these smaller groups, they were encouraged to engage in self-reflection and discussion with other female student-athletes. Committee members and selected individuals from the department served as facilitators. Finally, the entire group reconvened, and seniors shared insight from their student-athlete experience. Overall, this session highlighted the goal of pursuing life with intentionality. Collectively, the five interventions highlight norms, stereotypes, and expectations related to female athleticism and facilitate the recognition that the female student-athletes do not have to conform to them. Because the interventions celebrate their athleticism, provide an environment for growth, and allow them to interact with peers, they align with theories of student development. 


\section{Appendix B: Document analysis}

\section{Strategic Goal 2:}

Create programs and services that educate, encourage and inspire student-athletes and staff to achieve and sustain a culture that supports social responsibility, positive decisionmaking and healthy behavioral choices.

Specific Objective \#1:

Enable student-athletes and staff to identify, value and engage in socially responsible behaviors.

Specific Objective \#2:

Enable student-athletes and staff to identify, value and engage in socially responsible relationships.

Specific Objective \#3:

Enable student-athletes and staff to identify, value and engage in building and maintaining a socially responsible departmental environment.

\section{Implementation Strategies:}

1. Facilitate ongoing educational curricula through evidence-based tutorials, seminars and workshops to promote a culture of social responsibility.

2. Create a broadly based mentoring structure. In practice, everyone has a mentor; everyone is a mentor.

3. Regularly encourage and celebrate socially responsible behaviors through personal recognitions, awards and rewards.

4. Expect individual department members to personally engage through mentoring, staff meetings, team meetings, retreats and meetings with direct supervisors.

5. Recruit student-athletes and staff who possess the character and desire to succeed in [the] culture of social responsibility.

6. Create departmental policies for student-athletes and staff that define the expectations of social responsibility and identify significant violations and related consequences. 


\section{Appendix C: Interview Protocol}

\section{Agenda:}

1. Introduction

- "Thank you for being here today. I know it is a busy time of year. As you probably already know, my name is Alicia Hatcher, and I am doing research as part of my doctoral program here at the University of [XXXXXX]. For my dissertation, I have selected to complete a study on the empowerment of female student-athletes. I think the student-athlete experience is an important piece of college life, and I want to continue making it better for young women like you.

So, because you all have participated in an intervention aimed at empowering female student-athletes, I have invited you to participate in this research study. As part of the study, I will ask questions related to your experiences with the Women for Women programming. It will take about an hour of your time. I will also audio-record the discussion. The results of the study may help [the] staff shape further programming. The results may also inform the research base on female student-athlete empowerment in ways that will establish a platform for social responsibility education and implementation nationwide. So, honest responses that reflect your experiences will reveal the best results and are certainly appreciated.

Additionally, you are free to withdraw from participation at any time. You may also refuse to answer some or all of the questions. All of the information gained during the research process will remain confidential. My direct research supervisor, members of the research team, and I are the only individuals who will have access to the data. Your name and identity will not be attached to any of your comments. However, the data may be seen by an ethical review committee and may be published in a journal without giving your name or disclosing your identity." [Sign informed consent papers and begin the focus group interview.]

\section{Questions - Part 1}

- Tell me about your experience with the programming. (RQ 1)

- Tell me about the biggest messages you've gained through the programming, if any? (RQ 1)

- What components of the sessions stand out to you, if any? (RQ 1)

- How have you developed from the programming, if at all? (RQ 1,3)

- What pieces of the programming have influenced you, if any? (RQ 1,4)

$\circ$ In what ways?

- What other experiences influence your development? (RQ 1, 3)

○ In what ways?

- In what ways does the programming hinder your development? (RQ 1, 3)

O Why or why not? 


\section{Questions - Part 2}

\section{Psychological Empowerment}

- Tell me about how you view and feel about yourself. (RQ 2,3)

- What role does the programming play in that view?

- Tell me about your level of confidence and self-esteem. (RQ 2,3)

- What role does the programming play in those elements?

- Tell me about how you feel you can accomplish the tasks promoted in the programming. (RQ 2, 4)

- What is the most influential factor toward how you view yourself? (RQ 2,3)

- How have you developed personally as a result of the programming, if at all? (RQ $2,3)$

Interactional Empowerment

- Tell me about how much choice you feel you have in your life. (RQ 2)

- What role does the programming play?

- Tell me about what you feel are the most important topics facing female studentathletes (awareness). (RQ 2)

○ What role does the programming play?

- How well do you feel you can make meaningful progress toward goals in your life? (RQ 2)

- What role does the programming play?

- How much do you feel in control of your life? (RQ 2)

- What role does the programming play?

- To what extent do you feel you can influence what happens around you? (RQ 2)

- What role does the programming play?

- In what ways has your behavior changed or stayed the same as a result of the programming? (RQ 2, 4)

\section{Community Empowerment}

- Tell me about how well you feel connected to the other female student-athletes. (RQ 2, 3)

$\circ$ What role does the programming play?

- What type of influence has the programming had on your team? (RQ 2, 3, 4)

- Seen an influence on the female student-athletes as a whole?

- What types of changes have you seen or not seen with the female student-athletes over time? (RQ 2, 4)

- What do you think the programming is doing for the female student-athletes as a whole? (RQ 2, 4)

- Tell me about what does not do in respect to creating an environment for all female student-athletes. (RQ 2, 4)

\section{Overall Empowerment}

- Tell me about how empowered you feel. (RQ 3)

- What is the largest influence on that?

- What role does the programming play? 


\section{Influence on Behavior}

- Tell me about how your behavior has changed or not changed as a result of the Women for Women programming. (RQ 4)

\section{Conclusion}

- "Thank you for your participation. If you have any further questions related to this study you may contact me in room [XXX] of the [XXXX], at

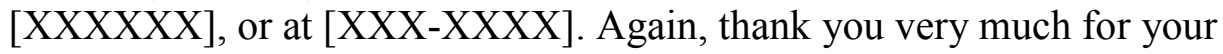
participation." 


\section{Appendix D: Informed consent}

\section{Title of Study:}

"Understanding the influence of social responsibility educational interventions on the empowerment of female student-athletes: A case study"

\section{Principle Investigator}

Alicia Hatcher

\section{Institution/Department}

University of [XXXXXX] Department of Athletics

\section{Introduction}

Thank you for being here today. I know it is a busy time of year. As you already know, my name is Alicia Hatcher, and I am doing research as part of my doctoral program here at the University of [XXXXXX]. For my dissertation, I have selected to complete a study on the empowerment of female student-athletes. I think the student-athlete experience is an important piece of college life, and I want to continue making it better for young women like you. So, because you have participated in an intervention aimed at empowering female student-athletes, I have invited you to participate further in this research study.

\section{Background Information}

The development of strong, brave, and courageous women in sport is necessary to break the cyclical transmission of knowledge and to enhance societal perceptions. Creating communities of empowered women who challenge the status quo of expectations related to womanhood, who value, respect, and appreciate their true selves, and who display these qualities through action is a primary goal and outcome during the empowerment process. Because of the characteristics associated with athleticism, including strength and determination, female student-athletes are seemingly ripe with relatively untapped po*tential for this type of development.

\section{Purpose}

Gaining insight into how female student-athletes make sense of social responsibility educational interventions is crucial for understanding their experiences of empowerment. Goals for the study include: (1) understanding how female student-athletes make sense of their development through the interventions; (2) gaining insight into the experiences of psychological, interactional, and community empowerment for female student-athletes; and (3) establishing research on how to best address the development of female studentathlete empowerment during the college experience.

\section{Procedures}

During the interview, I will ask questions related to your experiences with the Women for Women programming. It will take about an hour of your time. I will audio-record the discussion. 


\section{Risk}

Little risk on the part of participants exists because they will simply be asked to describe their experiences in an intervention they were already involved in. However, reflection on the intervention could bring the participant to think about problematic life events related to program topics.

\section{Right of Refusal}

You are free to withdraw from participation in the study at any time. You may also refuse to answer some or all of the questions. Any form of refusal will have no influence on your status as a student-athlete, as a member of your sport team, or as a member of any institutional club or organization.

\section{Confidentiality}

All information gained during the research process will remain confidential. My direct research supervisor, members of the research team, and I are the only individuals who will have access to the data. Additionally, your name and identity will not be attached to any of the data. However, the data may be seen by an ethical review committee and may be published in a journal, again, without revealing your name or disclosing your identity.

\section{Available Sources of Information}

If you have any further questions, you my contact Alicia Hatcher in room $[X X X]$ at the

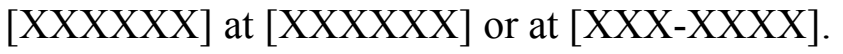

\section{Authorization}

I have read and understand this consent form, and I volunteer to participate in this research study. I understand that I will receive a copy of this form. I voluntarily choose to participate, but I understand that my consent does not take away any legal rights in the case of negligence or other legal fault of anyone who is involved in this study. I further understand that nothing in this consent form is intended to replace any applicable Federal, state, or local laws.

Participant's Name (Printed or Typed)

Date

Participant's Signature:

Date

Principal Investigator's Signature:

Date 
Alicia Hatcher, now Alicia Malnati, was born in Kansas City, Missouri. She grew up in Blue Springs, Missouri where she attended gymnastics at the Great American Gymnastics Express. She was always a good student and thrived at Blue Springs High School. She went on to study Journalism at the University of Missouri where she earned an athletic scholarship to the Mizzou Gymnastics Team. She competed for the Tigers from 2005-2009 and graduated with a degree in Magazine Journalism. She excelled during the student-athlete experience and took a graduate assistantship with studentathlete development in the fall of 2010 while pursuing a graduate degree in Educational Leadership and Policy Analysis.

Once graduated, she interned at the University of Georgia for a semester before returning again to student-athlete academic services for a graduate assistantship. She finished her coursework in Health Education and Promotion in May 2013 at the University of Missouri and soon accepted a position as an academic counselor with the University of Tennessee. She worked with the soccer and softball programs for one year at the Thornton Center before transitioning to the Center for Sport, Peace, and Society. She and her husband, Peter Malnati, a professional golfer, live in Knoxville, Tennessee. 